\title{
MINERALOGIA, MORFOLOGIA E ANÁLISE MICROSCÓPICA DE SOLOS DO BIOMA CERRADO(1)
}

\author{
J . B. V. GOMES(2), N. CURI (3), D. G. SCHULZE ${ }^{(4)}$, \\ J . J . G. S. M. MARQUES ${ }^{(5)}$, J . C. KER ${ }^{(6)}$ \& P. E. F. MOTTA ${ }^{(7)}$
}

\begin{abstract}
RESUMO
As características macro e micromorfológicas dos horizontes diagnósticos superficiais e subsuperficiais de Latossolos e Neossolos Quartzarênicos das superfícies Sul-Americana e Velhas foram estudadas em perfis sob cobertura de vegetação nativa, visando estabelecer um referencial para futuras comparações com áreas similares sob constante intervenção antrópica em termos de sustentabilidade. Com os solos referenciados por sub-região e pela superfície geomórfica que representam, três agrupamentos foram constituídos: Grupo 1: solos de textura argilosa a muito argilosa e hipo a mesoférricos; Grupo 2: solos de textura média a arenosa e hipoférricos, e Grupo 3: solos de textura argilosa a muito argilosa e férricos. O horizonte Bw dos Latossolos argilosos e muito argilosos estudados (Grupos 1e 3), com relações cauliníticas/(cauli nita + gibbsita) variando de 0,27 a 0,77, apresentaram grande coincidência de estrutura e microestrutura, respectivamente, forte muito pequena granular e de microagregados. Os solos do Grupo 2, Latossolos de textura média e um Neossolo
\end{abstract}

(1) Recebido para publicação em maio de 2003 e aprovado em maio de 2004.

(2) Pesquisador da Embrapa Tabuleiros Costeiros. Av. Beira-Mar 3250, CEP 49025-040 Aracaju (SE). E-mail: bosco@cpatc.embrapa.br

(3) Professor Titular do Departamento de Ciência do Solo, Universidade Federal de Lavras - UFLA. CEP 37200-000 Lavras (MG). Bolsista do CNPq. E-mail: niltcuri@ufla.br

(4) Professor, Agronomy Department, Purdue University, 47907-1150 West Lafayette-IN, USA. E-mail: dschulze@purdue.edu

(5) Professor Adjunto do Departamento de Ciência do Solo, UFLA. E-mail: jmarques@ufla.br

(6) Professor Adjunto do Departamento de Solos, Universidade Federal de Viçosa - UFV. CEP 36571-000 Viçosa (MG) E-mail: jcker@solos.ufv.br

(7) Pesquisador da Embrapa Solos. R. J ardim Botânico 1024, CEP 22460-000 Rio de J aneiro (RJ ). E-mail: motta@cnps.embrapa.br 
Quartzarênico, apresentaram o plasma preferencialmente como películas aderidas aos grãos que dominam o fundo matricial. A presença marcante de agregados na fração areia, resistentes ao tratamento para dispersão da terra fina, se deu apenas nos Latossolos argilosos e muito argilosos do Grupo 3 (com caráter férrico) e em parte do Grupo 1 (naqueles mais gibbsíticos). No leste de Goiás, o horizonte Bw dos perfis de G2, Latossolos Amarelos de mineralogia gibbsítica e isenta de hematita, apresentaram feições observadas em lâmina delgada de cor vermelha e agregados residuais da fração areia com hematita detectada pela difração de raios-X, aspectos que corroboram a hipótese de um pedoambiente mais úmido dessa posição na paisagem relativamente à posição G1, com perfis de Latossolos Vermelhos.

Termos de indexação: Latossolos, Neossolos Quartzarênicos, micromorfologia.

\title{
SUMMARY: MINERALOGY, MORPHOLOGY AND MICROSCOPIC ANALYSIS OF SOILS OF THE CERRADO BIOME
}

\begin{abstract}
The macro and micromorphological characteristics of the surface and subsurface diagnostic horizons of Oxisols and Quartzi psamments of the South American and Velhas geomorphic surfaces were analyzed in profiles under native vegetation cover, in order to establish a reference for future comparisons with similar areas under ongoing human intervention. Thesoils in their respectivesubregions and geomorphicsurfaces wereclassified in threegroups: Group 1: hypo to mesoferric, clayey to very dayey soils; Group 2: hypoferric; sandy to sandy loam soils, and Group 3: ferric, clayey to very clayey soils. TheBw horizons of the studied clayey and very clayey Oxisols (Groups 1 and 3), with kaol inite/ (kaolinite + gibbsita) ratio varying from 0.27 and 0.77 , present elevated similarity in macrostructure and mi crostructure, which aregranular. The soil plasma of Group 2 (sandy loam Oxisols and a Quartzipsament) is film-likeand is adhered to grains that aredomi nant in thematrix background. The marked presence of dispersion resistant aggregates in the sand fraction occurred only in Group 3 ferric clayey Oxisols and in more gibsitic Oxisols of Group 1. In Bw horizons of yellowish gibsitic Oxisol s of the G2 profiles from eastern Goiás, red colored thick sections and residual aggregates of thesand fraction with presence of hematitedetected by X-ray diffraction were observed. These features corroborate the hypothesis of a more humid pedoenvironment at this landscape position compared to that at position $\mathrm{G} 1$, where reddish Oxisol profiles are found.
\end{abstract}

Index terms: Oxisol, Entisol, micromorphology.

\section{INTRODUÇÃO}

A morfologia dos Latossolos é conhecida por apresentar a maior parte do plasma do horizonte $\mathrm{B}$ contido em agregados granulares muito pequenos, os microagregados (Vidal-Torrado et al., 1999). A expressão máxima dessa morfologia reflete-se na micromorfologia em uma trama grânica/granóidica e microestrutura granular/micropédica (Stoops \& Buol, 1985; Kalima \& Spaargaren, 1988; VidalTorrado \& Lepsch, 1993), mas variações de comportamento são comuns, dependendo, principalmente, da mineralogia da fração argila e da textura dos solos.
Os microagregados de solos tropicais intemperizados são muito resistentes e tiveram papel de destaque na formulação da hipótese da hierarquia da agregação dos sol os (Oades \& Waters, 1991). Mais recentemente, outros pesquisadores levantaram dados e novas hipóteses surgiram para explicar a maior resistência e durabilidade desses microagregados, quando comparados aos de solos menos intemperizados (Schulze \& Stott, 1997; Vrdoljak, 1998; Marques, 2000; Schaefer, 2001). Essa maior resistência é atestada pela dificuldade de se refletir o teor de argila em pegajosidade na textura avaliada pelo tato (Cline \& Buol, 1973). É muito citada a sensação inicial de areia ao tato de 
Latossolos argilosos e muito argilosos (Buol \& Eswaran, 2000), normalmente relacionada com as denominadas areia esiltefuncionais (Resende et al., 2002). Essa resistência faz com que, em Latossolos mais oxídicos, areia esilteinduam tambémagregados mais resistentes aos tratamentos de dispersão química e mecânica realizados na análise granulométrica.

Considerando que variações na morfologia latossólica ocorrem mesmo para os sol os das superfícies geomórficas da região dos Cerrados (onde ela é mais bem expressa), foi objetivo deste trabalho analisar a macro e micromorfologia dos horizontes diagnósticos superficiais e subsuperficiais de Latossol os e N eossol os Quartzarênicos das superfícies Sul-Americana e Vel has, sob cobertura vegetal nativa. Além disso, a observação pormenorizada dos atributos macro e micromorfológicos dos solos realça aspectos dos mais sensíveis à intervenção antrópica: estrutura, porosidade, permeabilidade, compactação e encrostamento do sol o (Bullock et al., 1985). Assim, a observação desses aspectos sob remanescentes de cobertura vegetal nativa, cada vez mais raros ou mesmo inexistentes (principalmente nas chapadas), servirá como referencial para futuras comparações com áreas similares sob constante intervenção antrópica, em termos de sustentabilidade.

\section{MATERIAL E MÉTODOS}

\section{Sub-regiões e amostragem}

A amostragem foi realizada em três sub-regiões: Leste de Goiás (G), Noroeste de Minas (N) e Triângulo Mineiro (T), considerando a repetição das superfícies geomórficas (Figura 1). Os solos amostrados correspondem às posições de paisagem com maior amplitude em cada superfície, o que coincide com posições de topo a meia encosta eár eas de elevado aproveitamento agrícola (Figura 1C). Amostraram-se três repetições, todas sob cobertura vegetal nativa, de 13 posições na paisagem, totalizando 39 perfis de solo.

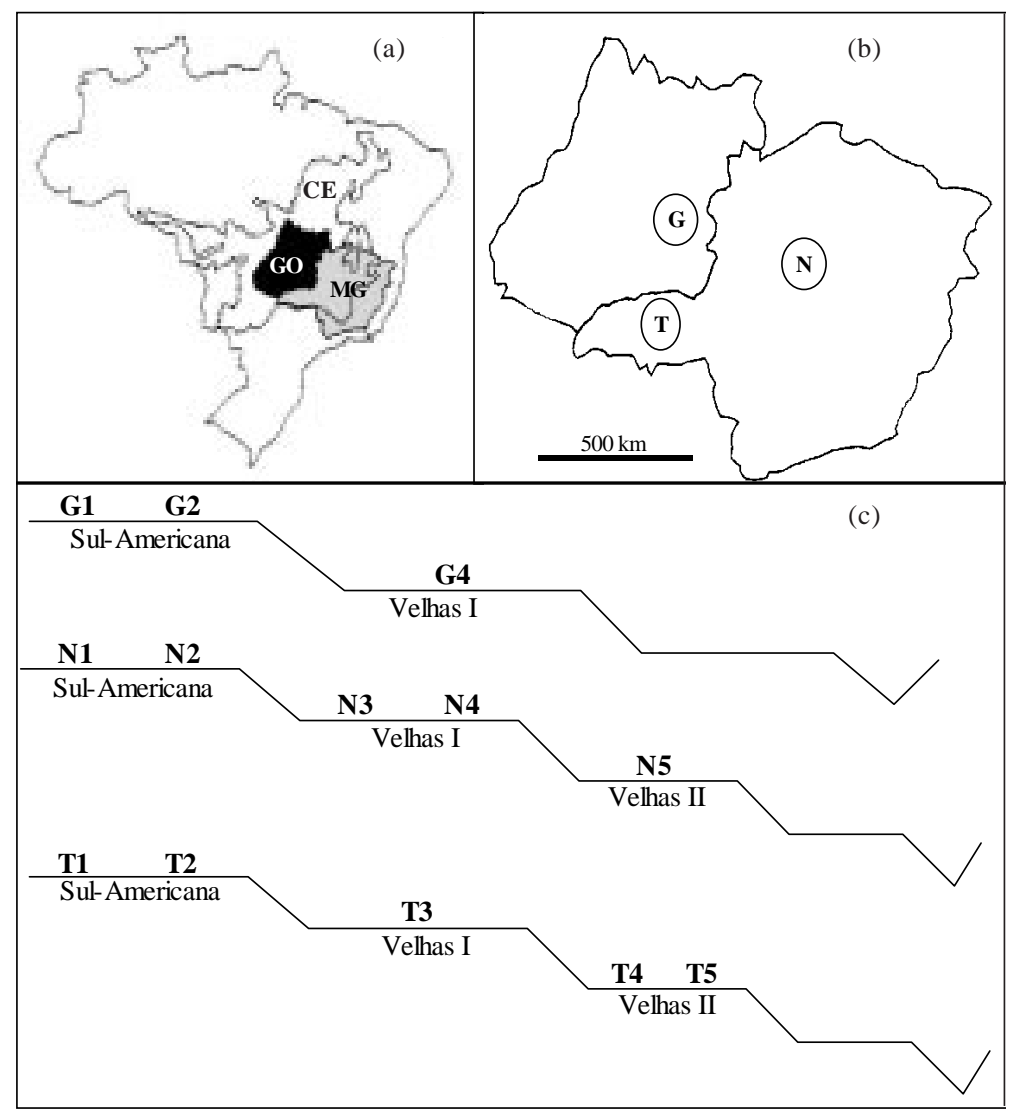

Figura 1. Mapa do Brasil mostrando a região dos Cerrados (CE) e os estados de Goiás (GO) e Minas Gerais (MG) (a). Mapa dos estados de Goiás e de Minas Gerais mostrando a localização aproximada das três áreas de estudo: leste de Goiás (G), noroeste de Minas Gerais (N) e Triângulo Mineiro (T) (b). Esquema mostrando as diferentes posições de amostragem (código dos perfis de solo), conforme a superfície geomórfica e a área de estudo (c). A distância horizontal em C está fora de escala entre as áreas e varia de dezenas a centenas de km (adaptado de Marques, 2000). 
Os dados de clima das três sub-regiões encontram-se em Gomes et al. (2004). Os sol os das diferentes posições de paisagem foram agrupados pela textura e teor de $\mathrm{Fe}_{2} \mathrm{O}_{3}$ do ataque sulfúrico (Quadro 1).

O perfil de cada solo representativo foi descrito em trincheira, segundo Lemos \& Santos (1996), sendo a amostragem realizada em duas profundidades $(0-0,2$ e $0,8-1,0 \mathrm{~m})$, totalizando 78 amostras. Cada amostra representa um horizonte diagnóstico, superficial ou subsuperficial, de cada pedon, estando representada por um código de quatro caracteres: (1) letras $\mathrm{G}, \mathrm{N}$ e T, que correspondem às sub-regiões já indicadas; (2) números 1-5, que representam diferentes posições na paisagem (Figura $1 C$ ); (3) letras A, B e C, que representam as três repetições de cada posição na paisagem de cada sub-região, e (4) números 1 e 2, respectivamente, horizontes diagnósticos; superficial (horizonte A) e subsuperficial (horizontes Bw, no caso de Latossolos, e C, no caso de Neossolos Quartzarênicos). O código, além do formato por amostra (por exemplo, N1C1), pode aparecer de forma parcial, referindo-se à posição na paisagem de determinada sub-região (por exemplo, N1) ou a um perfil específico (por exemplo, N1C). A morfologia ea granulometria foram realizadas para ototal das amostras. Para a análisemicromorfológica, col etaram-se amostras indeformadas em pelo menos uma repetição de todas as posições de paisagem, tendo sido as posições T4 e T5, com perfis de solo originados de basalto, amostradas em duas repetições. A mineralogia da fração argila eas areias foram examinadas e caracterizadas em uma repetição de cada posição na paisagem.

\section{Análises de solos}

As amostras deformadas foram secas ao ar, destorroadas e passadas em peneiras de malha de $2 \mathrm{~mm}$, para obtenção da terra fina seca ao ar (TFSA).

Quadro 1. I nformações ambientais dos perfis agrupados pela textura e teor de $\mathrm{Fe}_{2} \mathrm{O}_{3}$ do ataque sulfúrico dos solos (hi poférrico: teores <8\%; mesoférrico: teores variando de 8 a $<18 \%$, e férrico: teores de 18 a $<36 \%$, conforme E mbrapa, 1999)

\begin{tabular}{|c|c|c|c|c|c|}
\hline Sub-região & Código do perfil & Classificação(1) & Vegetação nativa & Declive & Altitude \\
\hline & & & & $\%$ & $\mathrm{~m}$ \\
\hline \multicolumn{6}{|c|}{ Grupo 1. Solos de textura argilosa a muito argilosa e hipo a mesoférricos ( 21 perfis) } \\
\hline \multirow[t]{6}{*}{ Leste de Goiás } & G1A, G1B e G1C & LVw & Cerrado & 1 & $990-1.130$ \\
\hline & G2A e G2C & LAw & Cerrado & $1-2$ & $990-1.080$ \\
\hline & G2B & LVAd & Cerrado & 1 & 1.000 \\
\hline & G4A & LVd & Floresta tropical subcaducifólia & 4 & 930 \\
\hline & G4B & LVwf & Floresta tropical subcaducifólia & 4 & 950 \\
\hline & $\mathrm{G} 4 \mathrm{C}$ & LVd & Cerrado & 4 & 860 \\
\hline \multirow[t]{2}{*}{ Noroeste de Minas } & $N 1 A, N 1 B, N 1 C$ & LVd & Cerrado & 1 & $900-920$ \\
\hline & $\mathrm{N} 2 \mathrm{~A}, \mathrm{~N} 2 \mathrm{~B}$ e $\mathrm{N} 2 \mathrm{C}$ & LVAd & Cerrado & 1 & $880-930$ \\
\hline \multirow[t]{2}{*}{ Triângulo Mineiro } & T1A, T1B e T1C & LVd típico & Cerrado & 1 & $920-940$ \\
\hline & T2A, T2B e T2C & LVAd & Cerrado & 1 & $970-980$ \\
\hline \multirow{5}{*}{ Noroeste de Minas } & Grupo 2. Solos de tex & tura média a arer & osa e hipoférricos (12 perfis) & & \\
\hline & N3A e N3C & LAdp & Cerrado & $0-3$ & 830 \\
\hline & N3B & LAd & Cerrado & 0 & 840 \\
\hline & $N 4 A, N 4 B$ e $N 4 C$ & RQo & Cerrado & $2-4$ & $750-770$ \\
\hline & N5A, N5B e N5C & LVd & Cerrado & $1-2$ & $530-580$ \\
\hline \multirow[t]{2}{*}{ Triângulo Mineiro } & ТЗА & LVdp & Cerrado & 1 & 820 \\
\hline & Т3В е Т3C & LVd & Cerrado & 1 & $710-790$ \\
\hline \multirow{3}{*}{ Triângulo Mineiro } & Grupo 3. Solos de textc & ¿ra argilosa a mui & to argilosa e férricos ( 6 perfis) & & \\
\hline & T4A, T4B, T5A e T5C & LVdf & Floresta tropical subcaducifólia & $1-4$ & $510-560$ \\
\hline & T4C e T5B & LVwf & Floresta tropical subcaducifólia & 1 & $520-540$ \\
\hline
\end{tabular}


A análise granulométrica seguiu as recomendações da Embrapa (1997). As relações moleculares $\mathrm{SiO}_{2} /$ $\mathrm{Al}_{2} \mathrm{O}_{3}(\mathrm{Ki})$ e $\mathrm{SiO}_{2} /\left(\mathrm{Al}_{2} \mathrm{O}_{3}+\mathrm{Fe}_{2} \mathrm{O}_{3}\right)(\mathrm{Kr})$ for am calculadas a partir das extrações de Fe, Al eSi após tratamento da TFSA com $\mathrm{H}_{2} \mathrm{SO}_{4}$ 1:1 (volume).

A quantificação da mineral ogia da fração argila foi feita a partir das razões obtidas dos difratogramas e da alocação dos val ores deSi, Al, FeeTi do ataque sulfúrico, método adaptado de Resende et al. (1987). Nas análises de difração de raios-X (DRX), foram separadas amostras de argila a partir da terra fina por sedimentação após dispersão com $\mathrm{NaOH}$ 1,0 $\mathrm{mol} \mathrm{L}^{-1}$ (E mbrapa, 1997).

A areia do horizonte subsuperficial, após dispersão da TFSA com $\mathrm{NaOH}$ de forma semel hante ao preparo da amostra para a granulometria (Embrapa, 1997), foi separada por tamisação nas frações: areia grossa $(2,0-0,2 \mathrm{~mm})$ e areia fina $(0,2-$ $0,05 \mathrm{~mm}$ ). As duas frações foram observadas em lupa bilocular, espal hando-se pequenas quantidades do material em placas de petri quarteadas, possibilitando a confecção de fotografias por câmera acoplada à bilocular e a quantificação dos grãos de quartzo, agregados que resistiram à dispersão da análise granulométrica e grãos de minerais escuros (incluindo magnéticos). Também foram realizadas observações de forma e cor dos materiais. Para aquelas amostras com quanti dades significativas de agregados e grãos escuros, foi realizada a DRX do material moído. Para separar os grãos escuros destas amostras, foram empregados um magneto de mão e uma fase líquida de elevada densidade (tetrabrometano, densidade $=2,9 \mathrm{Mg} \mathrm{m}^{-3}$ ). Os agregados foram separados manual mente. Todas as amostras foram testadas para reação à presença de $\mathrm{H}_{2} \mathrm{O}_{2}$ 1:1 a frio, visando à detecção de revestimentos de manganês.

As análises micromorfológicas foram realizadas em lâminas del gadas de 3,5 x 7,0 cm, confeccionadas a vácuo, com resina de poliéster (Fitzpatrick, 1984), a partir deamostras indeformadas, eobservadas em microscópio de luz plana, com polarização, Iuz refletida e transmitida da ZEISS, modelo AXIOPLAN. As análises seguiram critérios estabel ecidos em Brewer (1976), Bullock et al. (1985) e Lima et al. (1985). Para as mi crografias, empregouse o programa KS400 de análise de imagens da ZEISS, acoplado ao mi croscópio.

\section{RESULTADOS E DISCUSSÃO}

\section{Morfologia dos solos}

Ocorre grande dominância da estrutura forte muito pequena granular nos horizontes subsuperficiais, com variações nos Latossolos de textura média do Grupo 2 e uma exceção na estrutura em grãos simples dos perfis de N eossolos
Quartzarênicos da posição N4 (Quadro 2). Se a expressão da estrutura granular é favorecida pela presença de óxidos de Al e de Fe (Resende et al., 2002), mesmo os horizontes subsuperficiais dos L atossol os argil osos rel ativamente mais cauliníticos do Grupo 1 [perfis N1A e N2A, relação Ct/(Ct + Gb) de 0,69 e 0,77 , respectivamente, contra 0,27 do perfil G2A, o mais gibbsítico], apresentam estrutura forte muito pequena granular, típica dos Latossolos da região dos cerrados. Os solos do Grupo 3 apresentam relações $\mathrm{Ct} /(\mathrm{Ct}+\mathrm{Gb})$ entre 0,65 e 0,73 e são, marcadamente, de estrutura granular, influenciados pelo el evado teor de $\mathrm{Fe}_{2} \mathrm{O}_{3}$ que apresentam (Quadro 3).

O horizonte A de vários perfis, incluindo a quase total i dade daquel es sob vegetação nativa de fl oresta (G4A e todos os perfis do Grupo 3), apresenta uma estrutura em bl ocos subangulares de grau moderado a forte, conseqüência dos constantes ciclos de umedecimento e secagem sobre esse horizonte (Resende et al., 2002).

\section{Análise microscópica de areias dos horizontes subsuperficiais}

Alguns solos apresentam na sua fração areia quantidades expressivas de agregados residuais (Quadro 4 e Figuras 2, 3 e 4). As areias dos perfis do Grupo 3 (F igura 4), T4A e T5A, são aquelas com maiores quantidades desses agregados, influenciadas pelo el evado teor de $\mathrm{Fe}_{2} \mathrm{O}_{3}$ (299 e $281 \mathrm{~g} \mathrm{~kg}^{-1}$, para as amostras T4A2 e T5A2, respectivamente), fato associado ao material de origem (basalto) desses perfis de solos. PinheiroDick \& Schwertmann (1996), ao compararem a resistência à desagregação mecânica em diferentes Oxissolos, encontraram maior resistência naqueles com maior conteúdo de óxidos de Fe.

Os perfis das posições $\mathrm{G} 1$ e G2 (F iguras $2 \mathrm{a}$ e 2b), com 46 a $70 \%$ de agregados residuais na fração areia, são os de mineral ogia mais gibbsítica de todos os solos estudados, independentemente do teor de $\mathrm{Fe}_{2} \mathrm{O}_{3}$ e da relação $\mathrm{Gt} /(\mathrm{Gt}+\mathrm{Hm})$. A influência positiva da gibbsita (Gb) na estabilidade de agregados de Oxissolos, aqui se refletindo na quantidade de agregados resistentes ao tratamento para dispersão da análise granulométrica, foi citada por Bartoli et al. (1991). Ferreira et al. (1999) e Vitorino (2001) também afirmaram que Latossolos gibbsíticos desenvolvem estrutura granular muito resistente. Isso pode ser devido ao arranjamento esférico das placas de gibbsita e ao maior ponto isoel étrico desse mineral. Existe também a possibilidade de que os microagregados de Oxissol os apresentem um núcleo de matéria orgânica, indisponível ao ataque microbiano, à vol ta do qual as placas de gi bbsita se organizariam (Vrdoljak, 1998).

A presença de $21 \%$ de agregados residuais na fração areia fina do perfil T2A (Figura 2f) pode ser comparada com a ausência desses agregados no 
Quadro 2. Caracterização morfológica dos perfis agrupados pela textura e teor de Fe do ataque sulfúrico dos solos

\begin{tabular}{|c|c|c|c|c|}
\hline \multirow{2}{*}{ Perfil(1) } & \multicolumn{2}{|c|}{ Horizonte superficial } & \multicolumn{2}{|c|}{ Horizonte subsuperficial } \\
\hline & Cor úmida & Estrutura & Cor úmida & Estrutura \\
\hline \multicolumn{5}{|c|}{ Grupo 1. Solos de textura argilosa a muito argilosa e hipo a mesoférricos } \\
\hline G1 & $2,5 Y R 3 / 4$ & $\begin{array}{l}\text { Forte muito pequena } \\
\text { granular }\end{array}$ & $2,5 Y R \quad 3 / 6$ e $2,5 Y R 4 / 6$ & $\begin{array}{l}\text { Forte muito pequena } \\
\text { granular }\end{array}$ \\
\hline $\mathrm{G} 2$ & $10 Y R 3 / 3$ e $7,5 Y R 4 / 2$ & $\begin{array}{l}\text { Forte muito pequena } \\
\text { granular }\end{array}$ & 10YR 5/6, 4YR 4/7 e 9YR 5/8 & $\begin{array}{l}\text { Forte muito pequena } \\
\text { granular }\end{array}$ \\
\hline G4 & $2,5 Y R$ 3/3, 5YR 3/3 e 5YR 3/4 & $\begin{array}{l}\text { Moderada pequena e } \\
\text { média blocos } \\
\text { subangulares e forte } \\
\text { pequena granular }\end{array}$ & $10 R 3 / 6$ e $2,5 Y R$ R/7 & $\begin{array}{l}\text { Forte muito pequena } \\
\text { granular }\end{array}$ \\
\hline N 1 & $2,5 Y R 2,5 / 4$ & $\begin{array}{l}\text { Moderada muito } \\
\text { pequena granular }\end{array}$ & $2,5 Y R 3 / 6$ & $\begin{array}{l}\text { Forte muito pequena } \\
\text { granular (al guns } \\
\text { blocos subangulares) }\end{array}$ \\
\hline N2 & $5 Y R 4 / 4$ & $\begin{array}{l}\text { Moderada muito } \\
\text { pequena granular }\end{array}$ & $4 Y \mathrm{R} 4 / 6$ & $\begin{array}{l}\text { Forte muito pequena } \\
\text { granular }\end{array}$ \\
\hline $\mathrm{T} 1$ & $2,5 Y R 3 / 4$ & $\begin{array}{l}\text { Fraca a moderada } \\
\text { pequena a média } \\
\text { blocos subangulares }\end{array}$ & $2,5 Y R 3 / 6$ & $\begin{array}{l}\text { Forte muito pequena } \\
\text { granular }\end{array}$ \\
\hline T2 & $7,5 Y R 3 / 3$ & $\begin{array}{l}\text { Fraca pequena a } \\
\text { média granular }\end{array}$ & $5 Y R 4 / 6$ & $\begin{array}{l}\text { Forte muito pequena } \\
\text { granular }\end{array}$ \\
\hline \multicolumn{5}{|c|}{ Grupo 2. Solos de textura média a arenosa e hipoférricos } \\
\hline N3 & 10YR $3 / 2$ & $\begin{array}{l}\text { Moderada média } \\
\text { blocos subangulares } \\
\text { (alguns grânulos) }\end{array}$ & 10YR $4 / 4$ & $\begin{array}{l}\text { Forte pequena } \\
\text { granular }\end{array}$ \\
\hline N4 & $5 Y R 5 / 4$ & Grãos simples & $5 Y R 5 / 6$ & Grãos simples \\
\hline N5 & $2,5 Y R 3 / 4$ & $\begin{array}{l}\text { Moderada pequena } \\
\text { e média blocos } \\
\text { subangulares } \\
\text { (alguns grânulos) }\end{array}$ & $2,5 Y R \quad 4 / 6$ & $\begin{array}{l}\text { Forte muito pequena } \\
\text { granular }\end{array}$ \\
\hline T3 & $5 Y R 3 / 5$ & $\begin{array}{l}\text { Fraca pequena } \\
\text { a média granular }\end{array}$ & $2,5 Y R 3 / 6$ & $\begin{array}{l}\text { Fraca a moderada } \\
\text { muito pequena } \\
\text { granular }\end{array}$ \\
\hline \multicolumn{5}{|c|}{ Grupo 3. Solos de textura argilosa a muito argilosa e férricos } \\
\hline T4 & $10 \mathrm{R} 3 / 2$ & $\begin{array}{l}\text { Moderada a forte } \\
\text { pequena blocos } \\
\text { subangulares }\end{array}$ & $10 \mathrm{R} 3 / 5$ & $\begin{array}{l}\text { Forte muito pequena } \\
\text { granular }\end{array}$ \\
\hline T5 & $10 \mathrm{R} 3 / 2$ & $\begin{array}{l}\text { Moderada a forte } \\
\text { pequena a média } \\
\text { blocos subangulares }\end{array}$ & $10 \mathrm{R} 3 / 4$ & $\begin{array}{l}\text { Forte muito pequena } \\
\text { granular }\end{array}$ \\
\hline
\end{tabular}

(1) Perfis por posição na paisagem.

perfil T1A (Figura 2e). Eles apresentam relação Ct/ $(\mathrm{Ct}+\mathrm{Gb})$ do horizonte subsuperficial bem próxima (respectivamente, 0,54 e 0,58, para T1A2 e T2A2), mas diferem muito na relação $\mathrm{Gt} /(\mathrm{Gt}+\mathrm{Hm})$ (respectivamente, 0,14 e 0,77, para T1A2 eT2A2), o que está refletido na cor desses solos, respectivamente, vermel ho e vermelho-amarelo, para T1A e T2A. A maior resistência à dissolução da goethita (Gt), relativamente à hematita $(\mathrm{Hm})$, está bem documentada na literatura (Kämpf \& Curi, 2000), mas não éfeita nenhuma diferenciação entre a resistência de agregados goethíticos e hematíticos.

Para os sol os argil osos estudados, parece ocorrer uma interessante conjunção dos efeitos do teor de óxidos de Fe do ataque sulfúrico e das relações Ct/ $(\mathrm{Ct}+\mathrm{Gb})$ e $\mathrm{Gt} /(\mathrm{Gt}+\mathrm{Hm})$, estando os agregados resi duais na fração areia, e previstamente na fração silte (não analisada), associados aos valores muito elevados de óxidos de Fe (perfis T4A e T5A) e aos val ores muito baixos da relação $\mathrm{Ct} /(\mathrm{Ct}+\mathrm{Gb}$ ) (perfis G1A e G2C). Quando o teor de óxidos de Fe e a relação $\mathrm{Ct} /(\mathrm{Ct}+\mathrm{Gb}$ ) foram intermediários (perfis G4A, T1A eT2A), uma el evada relação Gt/(Gt + Hm) parece ter influenciado para que o material de solo ainda apresentasse quantidades expressivas de agregados residuais na fração areia, caso de T2A. Para os Latossolos de textura média, o efeito da mineral ogia ficou diluído pela textura mais grosseira 
Quadro 3. Teores de argila, $\mathrm{Fe}_{2} \mathrm{O}_{3}$ do ataque sulfúrico e índices $\mathrm{Ki}$ e $\mathrm{Kr}$ da fração terra fina seca ao ar e características mineralógicas de amostras de solo selecionadas

\begin{tabular}{|c|c|c|c|c|c|c|c|}
\hline Amostra & Horizonte & Argila & $\mathrm{Fe}_{2} \mathrm{O}_{3}$ & $\mathbf{K i}$ & $\mathbf{K r}$ & $\mathbf{G t} /(\mathbf{G t}+\mathbf{H} \mathbf{m})^{(\mathbf{1})}$ & $\mathbf{C t} /(\mathbf{C t}+\mathbf{G b})^{(\mathbf{1})}$ \\
\hline \multicolumn{8}{|c|}{$\mathrm{g} \mathrm{kg}^{-1}$} \\
\hline \multicolumn{8}{|c|}{ Grupo 1. Solos de textura argilosa a muito argilosa e hipo a mesoférricos } \\
\hline $\begin{array}{l}\text { G1A1 } \\
\text { G1A2 } \\
\text { G2C1 } \\
\text { G2C2 } \\
\text { G4A1 } \\
\text { G4A2 } \\
\text { N1A1 } \\
\text { N1A2 } \\
\text { N2A1 } \\
\text { N2A2 } \\
\text { T1A1 } \\
\text { T1A2 } \\
\text { T2A1 } \\
\text { T2A2 }\end{array}$ & $\begin{array}{l}A \\
B \\
A \\
B \\
A \\
B \\
A \\
B \\
A \\
B \\
A \\
B \\
A \\
B\end{array}$ & $\begin{array}{l}640 \\
729 \\
608 \\
685 \\
527 \\
615 \\
417 \\
522 \\
382 \\
467 \\
469 \\
521 \\
660 \\
763\end{array}$ & $\begin{array}{r}138,3 \\
137,6 \\
83,8 \\
88,5 \\
106,1 \\
120,3 \\
83,2 \\
98,8 \\
95,1 \\
98,5 \\
83,2 \\
98,8 \\
95,1 \\
98,5\end{array}$ & $\begin{array}{l}0,53 \\
0,53 \\
0,54 \\
0,35 \\
0,91 \\
0,77 \\
1,16 \\
1,09 \\
1,25 \\
1,26 \\
0,86 \\
0,80 \\
0,87 \\
0,88\end{array}$ & $\begin{array}{l}0,43 \\
0,44 \\
0,48 \\
0,31 \\
0,73 \\
0,62 \\
0,91 \\
0,88 \\
1,02 \\
1,05 \\
0,70 \\
0,64 \\
0,75 \\
0,75\end{array}$ & $\begin{array}{l}0,48 \\
0,49 \\
1,00 \\
1,00 \\
0,62 \\
0,27 \\
0,36 \\
0,37 \\
1,00 \\
0,42 \\
0,13 \\
0,14 \\
1,00 \\
0,77\end{array}$ & $\begin{array}{l}0,40 \\
0,38 \\
0,41 \\
0,27 \\
0,62 \\
0,54 \\
0,72 \\
0,69 \\
0,77 \\
0,77 \\
0,53 \\
0,54 \\
0,59 \\
0,58\end{array}$ \\
\hline \multicolumn{8}{|c|}{ Grupo 2. Solos de textura média a arenosa e hipoférricos } \\
\hline $\begin{array}{l}\text { N3A1 } \\
\text { N3A2 } \\
\text { N4A1 } \\
\text { N4A2 } \\
\text { N5A1 } \\
\text { N5A2 } \\
\text { T3A1 } \\
\text { T3A2 }\end{array}$ & $\begin{array}{l}A \\
B \\
A \\
C \\
A \\
B \\
A \\
B\end{array}$ & $\begin{array}{r}108 \\
148 \\
77 \\
67 \\
150 \\
219 \\
79 \\
128\end{array}$ & $\begin{array}{l}25,5 \\
16,1 \\
22,1 \\
11,0 \\
28,1 \\
36,2 \\
37,2 \\
40,1\end{array}$ & $\begin{array}{l}0,76 \\
0,81 \\
1,45 \\
1,68 \\
1,63 \\
1,66 \\
0,73 \\
0,74\end{array}$ & $\begin{array}{l}0,67 \\
0,70 \\
1,21 \\
1,42 \\
1,29 \\
1,34 \\
0,57 \\
0,58\end{array}$ & $\begin{array}{l}1,00 \\
1,00 \\
0,00 \\
0,00 \\
0,37 \\
0,45 \\
0,50 \\
0,51\end{array}$ & $\begin{array}{l}0,53 \\
0,55 \\
0,81 \\
0,91 \\
1,00 \\
0,92 \\
0,52 \\
0,51\end{array}$ \\
\hline \multicolumn{8}{|c|}{ Grupo 3. Solos de textura argilosa a muito argilosa e férricos } \\
\hline $\begin{array}{l}\text { T4A1 } \\
\text { T4A2 } \\
\text { T5A1 } \\
\text { T5A2 }\end{array}$ & $\begin{array}{l}A \\
B \\
A \\
B\end{array}$ & $\begin{array}{l}524 \\
697 \\
504 \\
624\end{array}$ & $\begin{array}{l}295,5 \\
299,3 \\
307,7 \\
281,3\end{array}$ & $\begin{array}{l}0,98 \\
0,92 \\
1,09 \\
1,05\end{array}$ & $\begin{array}{l}0,55 \\
0,53 \\
0,64 \\
0,62\end{array}$ & $\begin{array}{l}0,00 \\
0,00 \\
0,00 \\
0,00\end{array}$ & $\begin{array}{l}0,67 \\
0,65 \\
0,73 \\
0,71\end{array}$ \\
\hline
\end{tabular}

(1) Ct: caulinita; Gt: goethita; Hm: hematita; Gb: gibbsita.

Quadro 4. Teores de quartzo, agregados residuais e minerais escuros da fração areia de horizontes subsuperficiais selecionados dos solos estudados

\begin{tabular}{|c|c|c|c|c|c|c|c|c|}
\hline \multirow[b]{2}{*}{ Perfil } & \multicolumn{4}{|c|}{ Areia fina $(<0,2 \mathrm{~mm})$} & \multicolumn{4}{|c|}{ Areia grossa $(>0,2 \mathrm{~mm})$} \\
\hline & $\begin{array}{l}\text { Total } \\
\text { TFSA(1) }\end{array}$ & Quartzo & $\begin{array}{c}\text { Agregados } \\
\text { residuais }\end{array}$ & $\begin{array}{l}\text { Minerais } \\
\text { escuros }\end{array}$ & $\begin{array}{c}\text { Total } \\
\text { TFSA(1) }\end{array}$ & Quartzo & $\begin{array}{l}\text { Agregados } \\
\text { residuais }\end{array}$ & $\begin{array}{c}\text { Minerais } \\
\text { escuros }\end{array}$ \\
\hline & $\mathrm{g} \mathrm{kg}^{-1}$ & $\ldots$ & $\%$ & + & $\mathrm{g} \mathrm{kg}^{-1}$ & $\longrightarrow$ & $\%$ & + \\
\hline \multicolumn{9}{|c|}{ Grupo 1. Solos de textura argilosa a muito argilosa e hipo a mesoférricos } \\
\hline $\begin{array}{l}\text { G1A } \\
\text { G2C } \\
\text { G4A } \\
\text { N1A } \\
\text { N2A } \\
\text { T1A } \\
\text { T2A }\end{array}$ & $\begin{array}{r}80 \\
66 \\
99 \\
220 \\
186 \\
246 \\
56\end{array}$ & $\begin{array}{l}47 \\
47 \\
89 \\
97 \\
99 \\
98 \\
76\end{array}$ & $\begin{array}{r}53 \\
52 \\
5 \\
- \\
- \\
- \\
21\end{array}$ & $\begin{array}{l}1 \\
1 \\
5 \\
2 \\
1 \\
2 \\
3\end{array}$ & $\begin{array}{r}36 \\
81 \\
35 \\
183 \\
239 \\
137 \\
75\end{array}$ & $\begin{array}{l}28 \\
54 \\
84 \\
98 \\
99 \\
98 \\
97\end{array}$ & $\begin{array}{r}70 \\
46 \\
- \\
0 \\
0 \\
0 \\
1\end{array}$ & $\begin{array}{r}3 \\
1 \\
16 \\
2 \\
0 \\
2 \\
2\end{array}$ \\
\hline \multicolumn{9}{|c|}{ Grupo 2. Solos de textura média a arenosa e hipoférricos } \\
\hline $\begin{array}{l}\text { N3A } \\
\text { N4A } \\
\text { N5A } \\
\text { T3A }\end{array}$ & $\begin{array}{l}335 \\
793 \\
535 \\
625\end{array}$ & $\begin{array}{r}99 \\
100 \\
98 \\
98\end{array}$ & $\begin{array}{l}0 \\
0 \\
0 \\
0\end{array}$ & $\begin{array}{l}1 \\
1 \\
2 \\
2\end{array}$ & $\begin{array}{r}461 \\
58 \\
105 \\
165\end{array}$ & $\begin{array}{r}100 \\
100 \\
88 \\
99\end{array}$ & $\begin{array}{l}0 \\
0 \\
3 \\
0\end{array}$ & $\begin{array}{l}0 \\
0 \\
9 \\
0\end{array}$ \\
\hline \multicolumn{9}{|c|}{ Grupo 3. Solos de textura argilosa a muito argilosa e férricos } \\
\hline $\begin{array}{l}\text { T4A } \\
\text { T5A }\end{array}$ & $\begin{array}{r}49 \\
100\end{array}$ & $\begin{array}{l}13 \\
16\end{array}$ & $\begin{array}{l}77 \\
64\end{array}$ & $\begin{array}{l}11 \\
21\end{array}$ & $\begin{array}{l}17 \\
20\end{array}$ & $\begin{array}{l}13 \\
24\end{array}$ & $\begin{array}{l}81 \\
67\end{array}$ & $\begin{array}{r}6 \\
10\end{array}$ \\
\hline
\end{tabular}



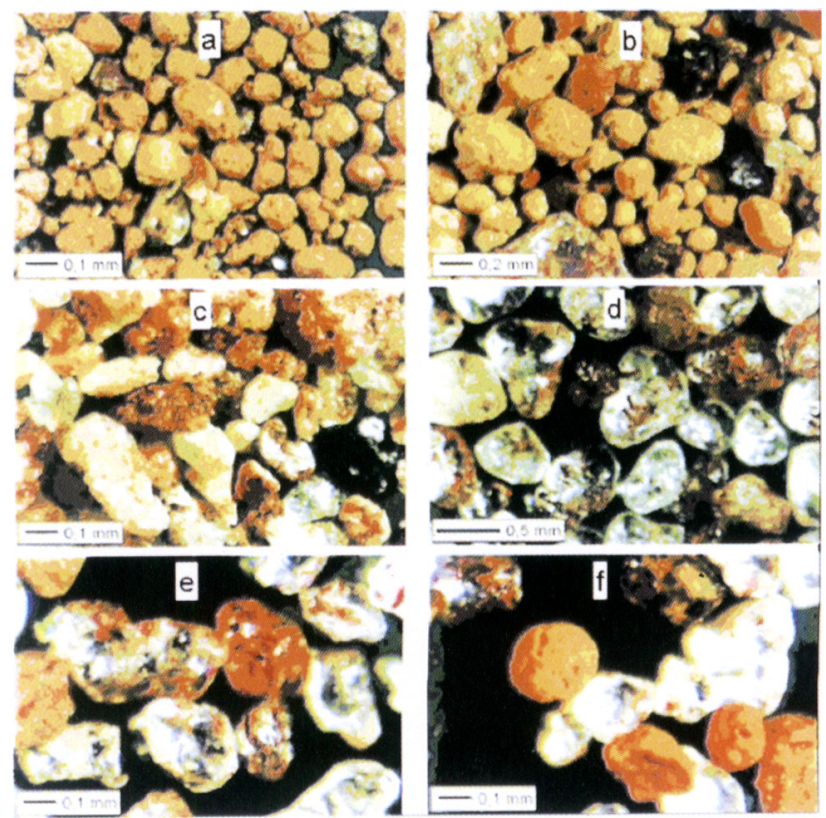

Figura 2. Fotografias de amostras de horizontes subsuperficiais (Bw), Grupo 1 (solos de textura argi losa a muito argil losa e hipo a mesoférricos): Areia fina, perfil G2C, com grande quantidade de agregados residuais (a); Areia grossa, perfil G2C, com grande quantidade de agregados residuais, reparar agregados mais vermelhos (o maior em cima e ao centro) e alguns minerais escuros (b); Areia fina, perfil G4A, com dominância de grãos de quartzo angulares avermelhados e foscos, reparar mineral escuro à direita (c); Areia grossa, perfil N2A, com dominância de grãos de quartzo arredondados e hialinos, parcialmente avermelhados, reparar mineral escuro ao centro (d); Areia fina, perfil T1A, com domi nância de grãos de quartzo subangulares a subarredondados avermelhados e hialinos (e); Areia fina, perfil T2A, com agregados residuais e grãos de quartzo subarredondados e hialinos, reparar mineral escuro em cima ao centro (f).

dos solos, pois seria o caso de N3A, um Latossolo Amarelo (LA) com relação $\mathrm{Ct} /(\mathrm{Ct}+\mathrm{Gb})$ de 0,55, mostrar alguma quanti dade de agregados residuais na fração areia, o que não ocorreu (Figura 3).

Nenhuma das amostras de areia apresentou reação à presença de peróxido de hidrogênio, sendo consideradas virtualmente isentas de materiais mangânicos.

\section{Mineralogia das areias}

Para todas as amostras, de todos os grupos, o quartzo (Qz) é o mineral predominante nas frações areia fina egrossa, como constatado a partir da DRX dessas frações.

No grupo 1, os agregados resi duais do perfil G1A, um Latossolo Vermel ho (LV), consistem de uma mistura deQz, Gb, H m, caulinita (Ct) e Gt (Quadro 5 eF igura 5). No perfil G2C, um LA, cuja mineralogia da fração argila evidenciou ausência de $\mathrm{Hm}$ [relação $\mathrm{Gt} /(\mathrm{Gt}+\mathrm{Hm})=1$, Quadro 3], foi confirmada essa ausência nos agregados da fração areia fina. Nos agregados da fração areia grossa, a $\mathrm{H} m$ foi detectada e refletea presença defei ções vermel has observadas nos agregados residuais (Figura 2b). Essas feições vermelhas também são observadas na lâmina delgada do horizonte Bw (Figura 8e). É bastante lógico admitir que a presença desses agregados residuais vermelhos tenha influenciado a detecção da $\mathrm{Hm}$ pela DRX.

No Grupo 3, os agregados de T4A e T5A confirmam a ausência de Gt na fração argila (Quadros 3 e 5 e Figura 6), o que os diferencia dos

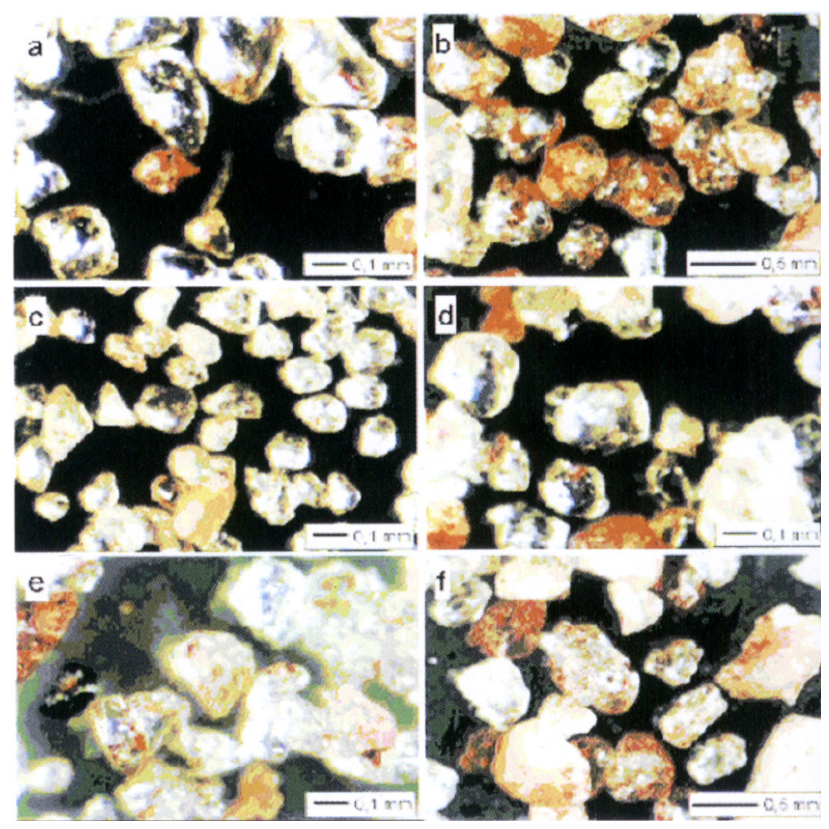

Figura 3. Fotografias de amostras de horizontes subsuperficiais (Bw e C), Grupo 2 (solos de textura média a arenosa e hipoférricos): Areia fina, perfil N3A, com grãos de quartzo subarredondados, hialinos e parcialmente avermelhados (a); Areia grossa, perfil N3A, com grãos de quartzo arredondados, hialinos e avermelhados, reparar mineral escuro em cima à direita (b); Areia fina, perfil N4A, com grãos de quartzo subarredondados e hialinos (c); Areia fina, perfil N5A, com grãos de quartzo subarredondados, hialinos e parcialmente avermelhados (d); Areia fina, perfil T3A, com grãos de quartzo angulares a subangulares, hialinos e parcialmente avermel hados, reparar mineral escuro à esquerda (e); Areia grossa, perfil T3A, com grãos de quartzo subangulares a arredondados, foscos a hialinos e parcialmente avermelhados, reparar mineral escuro em cima ao centro (f). 
Quadro 5 Composi ção mineralógica(1) ${ }^{(1)}$ fração areia de horizontes subsuperficiais selecionados dos solos estudados

\begin{tabular}{|c|c|c|c|c|}
\hline \multirow{2}{*}{ Perfil } & \multicolumn{2}{|c|}{ Agregado residual } & \multicolumn{2}{|c|}{$\begin{array}{l}\text { Agregado residual e nódulo de mineral } \\
\text { pesado e, ou, magnético }\end{array}$} \\
\hline & Areia fina & Areia grossa & Areia fina & Areia grossa \\
\hline & \multicolumn{4}{|c|}{ Grupo 1. Solos de textura argilosa a muito argi losa e hipo a mesoférricos } \\
\hline G1A & $\mathrm{Qz}, \mathrm{Gb}, \mathrm{Hm}, \mathrm{Ct}, \mathrm{Gt}$ & Qz, Gb, Ct, Gt, Hm & - & - \\
\hline $\mathrm{G} 2 \mathrm{C}$ & $\mathrm{Qz}, \mathrm{Gb}, \mathrm{Ct}, \mathrm{Gt}$ & $\mathrm{Qz}, \mathrm{Gb}, \mathrm{Hm}, \mathrm{Ct}, \mathrm{Gt}$ & - & - \\
\hline G4A & - & - & $\mathrm{Qz}, \mathrm{Hm}$ & - \\
\hline \multicolumn{5}{|c|}{ Grupo 3. Solos de textura argilosa a muito argilosa e férricos } \\
\hline $\mathrm{T} 4 \mathrm{~A}$ & $\mathrm{Qz}, \mathrm{Hm}, \mathrm{Gb}, \mathrm{II}, \mathrm{Mt}, \mathrm{Mh}$ & $\mathrm{Qz}, \mathrm{Hm}, \mathrm{Gb}, \mathrm{II}, \mathrm{Mt}, \mathrm{Mh}$ & $\mathrm{Hm}, \mathrm{II}, \mathrm{Mt}, \mathrm{Mh}$ & $\mathrm{Hm}, \mathrm{Mt}, \mathrm{Gb}, \mathrm{Qz}, \mathrm{An}, \mathrm{Mh}$ \\
\hline T5A & Qz, Hm, Gb, II & $\mathrm{Qz}, \mathrm{Hm}, \mathrm{Gb}, \mathrm{II}$ & $\mathrm{Hm}, \mathrm{Mt}, \mathrm{II}, \mathrm{Qz}, \mathrm{Gb}, \mathrm{Mh}$ & $\mathrm{Hm}, \mathrm{Qz}, \mathrm{Gb}, \mathrm{Mt}$ \\
\hline
\end{tabular}

(1) Qz: quartzo; Ct: caulinita; Gb: gibbsita; Gt: goethita; Hm: hematita; II: ilmenita; Mt: magnetita; Mh: maghemita; e An: anatásio.

agregados deL Vs férricos estudados por Pinheiro-Didk \& Schwertmann (1996). Agregados de ambos os perfisapresentamilmenita (II), enquantoa magnetita (Mt) e a maghemita (Mh) foram detectadas apenas nas amostras deT4A, sendo esses três componentes menores somados a anatásio e rutilo nos agregados estudados por Pinheiro-Dick \& Schwertmann (1996).

Os materiais pesados e magnéticos (minerais escuros e eventuais agregados e nódulos) dos perfis do Grupo 3 basicamente repetem a composição mineralógica dos agregados, com maior intensidade dos reflexos referentes aos minerais $\mathrm{Mt}$, II e Mh. O perfil G4A apresentou apenas Qz e Hm na composição dos minerais/agregados col ecionados como pesados e magnéticos (Quadro 5 e Figura 7).

\section{Micromorfologia}

Os sol os argi losos e muito argi losos dos Grupos $1 \mathrm{e}$ 3 apresentam grande dominância das microestruturas granulares (microagregados discretos) egranulares adensadas (microagregados coal escidos), que correspondem às tramas (grânica e granóidica) descritas para Latossolos (Lima, 1988; Ferreira et al., 1999; Vidal-Torrado \& Lepsch, 1999; VidalTorrado et al., 1999) (Quadro 6 e Figuras 8, 9 e 11). Pode-se ainda notar que os perfis N1A e N2A, os mais cauliníticos dos solos argilosos (Quadro 3), apresentam os microagregados menos bem expressos relativamente aos outros perfis desse Grupo nos horizontes subsuperficiais, nada comparável, entretanto, ao plasma contínuo e denso de Latossol os extremamente caul iníticos originados de sedimentos do Grupo Barreiras (Ferreira et al., 1999).

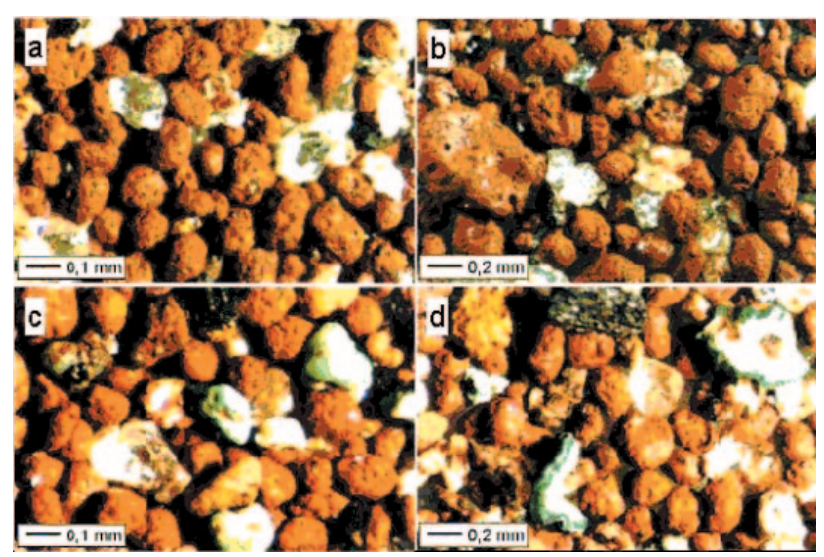

Figura 4. Fotografias de amostras de horizontes subsuperficiais (Bw), Grupo 3 (solos de textura argilosa a muito argilosa e fér ricos): Areia fina, perfil T4A, com grande quantidade de agregados residuais (a); Areia grossa, perfil T4A, com grande quantidade de agregados residuais, reparar alguns minerais escuros (b); Areia fina, perfil T5A, com grande quantidade de agregados residuais, reparar alguns minerais escuros e grãos de calcedônea (esverdeados) (c); Areia grossa, perfil T5A, com grande quantidade de agregados residuais, reparar alguns minerais escuros e grãos de calcedônea (d).

Comparando os solos aqui estudados com o Latossolo Una distrófico (atual Latossol o Vermel hoAmarelo), de plasma intermediário entre porfirogrânico e aglutinado, estudado por Ferreira et al. (1999), oúltimo se apresenta com uma relação 

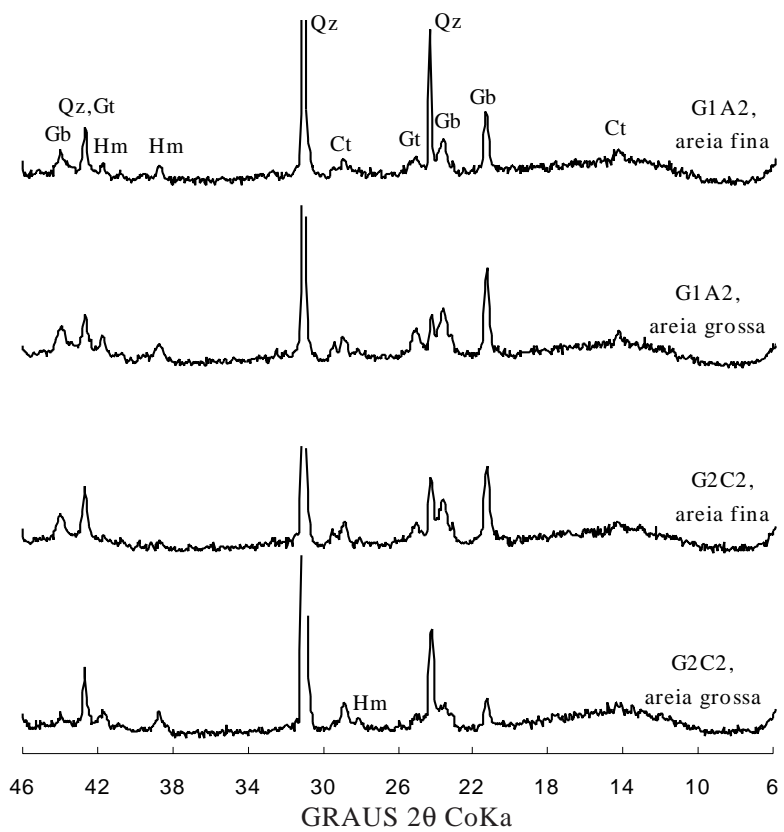

Figura 5. Difratogramas de raios-X de agregados residuais da fração areia de horizontes subsuperficiais (Bw), Grupo 1 (solos de textura argilosa a muito argilosa e hipo a mesoférricos; G1A = Latossolo Vermel ho ácríco típico e G2C = Latossolo Amarelo ácrico típico): Ct - caulinita, Gb - gibbsita, Gt - goethita, Hm - hematita e Qz - quartzo.
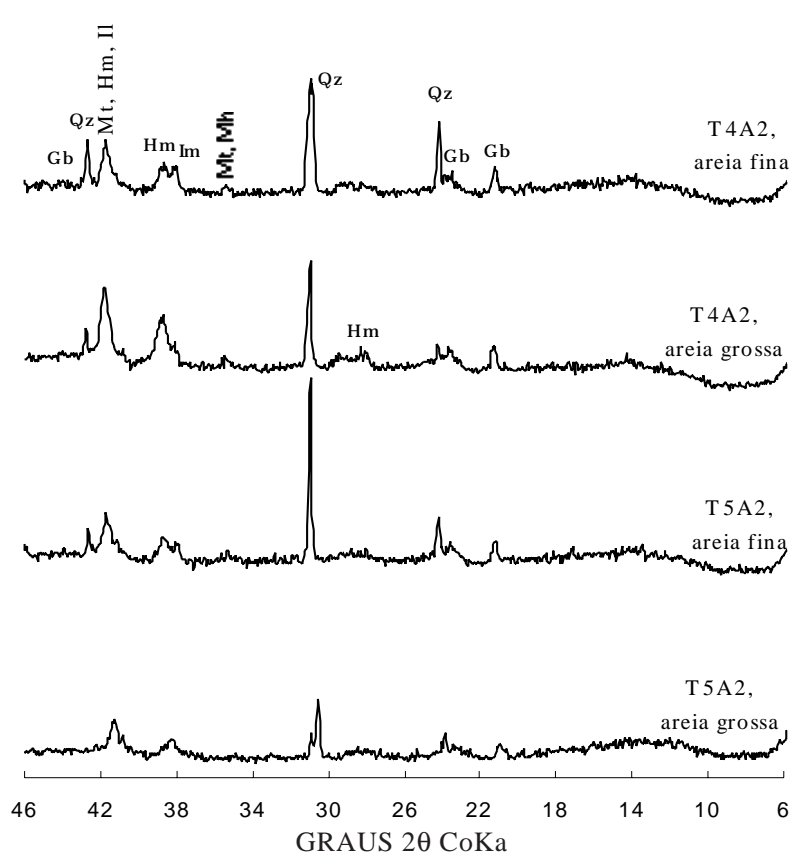

Figura 6. Difratogramas de raios-X de agregados residuais da fração areia de horizontes subsuperficiais (Bw), Grupo 3 (solos detextura argi losa a muito argilosa e férricos; T4A e T5A = Latossolos Vermelhos distroférricos típicos): Gb - gibbsita, Hm - hematita, II - I Imenita, Mh maghemita, Mt - magnetita e Qz - quartzo.

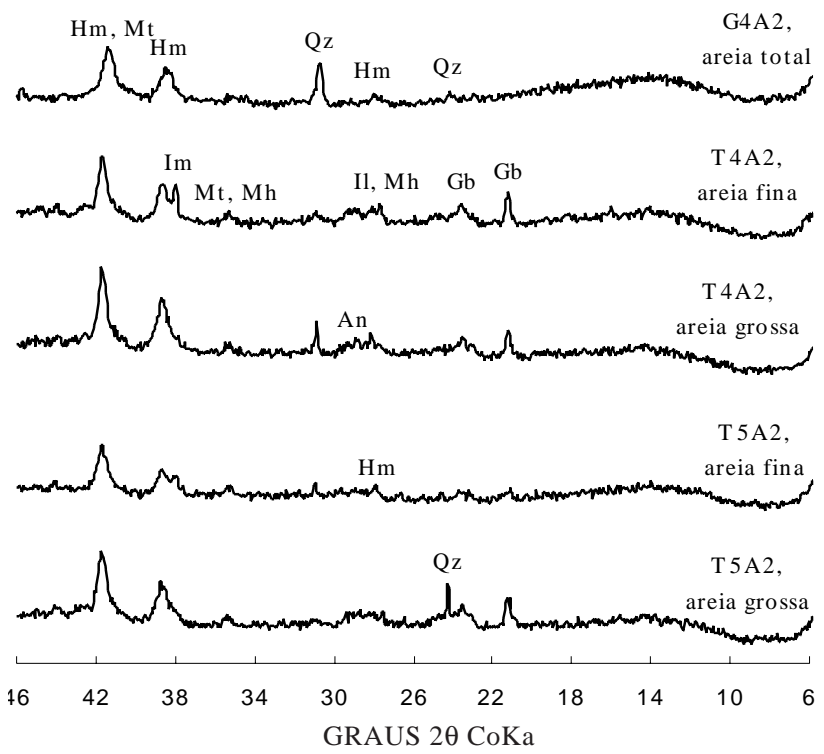

Figura 7. Difratogramas de raios-X de minerais e agregados residuais pesados (densidade $>2,9 \mathrm{Mg} \mathrm{m}^{-3}$ ) e magnéticos da fração areia de horizontes subsuperficiais (Bw) dos perfis G4A (Latossolo Vermelho distrófico típico), T4A e T5A (ambos Latossolos Vermelhos distroférricos típicos): An - anatásio, Gb - gibbsita, Hm hematita, II - IImenita, Mh - maghemita, Mt magnetita e Qz - quartzo.

$\mathrm{Ct} /(\mathrm{Ct}+\mathrm{Gb})$ de 0,91 contra 0,77 da amostra mais caulinítica do Grupo 1 (horizontes A e B do perfil N2A). Cabe ressaltar a boa expressão da microestrutura granular nos solos do Grupo 3, influenciada pel o caráter férrico desses solos.

Os solos do Grupo 2, de textura mais grosseira, apresentam microestrutura do tipo de grãos interligados e de grãos com películas, ocorrendo também inclusão de microestrutura com microagregados entre grãos (Figura 10). A subdomi nância de microagregados em L atossol os de textura média (Quadro 7) já tinha sido mencionada por Lima (1988), com o plasma formando preferivelmente massas aderidas aos grãos que dominam o fundo matricial, embora possam ocorrer Latossolos de textura média mais próxima aos limites da textura argilosa com predominância de microagregados, como aquele estudado por Santos et al. (1989). Dessa forma, as diferentes mineral ogias não produziram grandes diferenças demicroestrutura, bem como já não tinham apresentado na estrutura (Quadro 2), sendo excedidas pelo efeito da textura dos diferentes solos.

E m cada perfil, os horizontes subsuperficiais (Bw) dos Grupos 1 e 3 apresentam, relativamente aos horizontes superficiais, melhor distinção dos microagregados, mais discretos (Figura $8 b$ ) ou mais coalescidos (Figura 9b). A maior atividade biológica (como canais deixados pela fauna nas Figura 8a, $8 \mathrm{f}$ 


\section{Quadro 6. Características micromorfológicas de perfis de solo selecionados, agrupados pela textura e teor de Fe do ataque sulfúrico dos solos}

\begin{tabular}{llcl}
\hline Perfil Horizonte & $\begin{array}{c}\text { Microestrutura (ordem } \\
\text { decrescente de ocorrência) }\end{array}$ & Tipo de poro & $\begin{array}{c}\text { Observações sobre nódulos ou outros } \\
\text { aspectos relevantes }\end{array}$
\end{tabular}

Grupo 1. Solos de textura argilosa a muito argilosa e hipo a mesoférricos

\begin{tabular}{|c|c|c|}
\hline G1A & $A$ & Granular adensada e granular \\
\hline G1A & B & $\begin{array}{l}\text { Granular e de canais (na pare } \\
\text { dos agrotúbulos) }\end{array}$ \\
\hline G2A & A & Granular adensada e granular \\
\hline G2A & $B$ & Granular e granular adensada \\
\hline G4A & A & $\begin{array}{l}\text { De canais e granular adensa } \\
\text { (inclusão de camaras) }\end{array}$ \\
\hline G4A & B & Granular adensada e granul \\
\hline$N 1 A$ & $A$ & Granular adensada e granul \\
\hline$N 1 A$ & B & Granular adensada e granul \\
\hline $\mathrm{N} 2 \mathrm{~A}$ & $A$ & Granular adensada e granular \\
\hline $\mathrm{N} 2 \mathrm{~A}$ & B & Granular adensada e granul \\
\hline T1A & A & $\begin{array}{l}\text { Granular adensada e de can } \\
\text { (inclusão granular) }\end{array}$ \\
\hline T1A & B & Granular e granular adensada \\
\hline $\mathrm{T} 2 \mathrm{~A}$ & A & Granular adensada e granul \\
\hline $\mathrm{T} 2 \mathrm{~A}$ & $\mathrm{~B}$ & Granular e granular adensa \\
\hline
\end{tabular}

De empacotamento

De empacotamento

De empacotamento

De empacotamento

Canais, cavidades,

alvéolos e de

empacotamento

De empacotamento e

canais

De empacotamento

De empacotamento

De empacotamento

De empacotamento

De empacotamento e

canais

De empacotamento

De empacotamento

De empacotamento
Alguns agregados e nódulos amarelados no plasma vermelho.

Dois agrotúbulos semi-íntegros; parede externa dos agrotúbulos com baixa pedalidade.

Alguns agregados vermelhos.

Nódulos e muitos agregados vermelhos no plasma amarelo.

Nódulos pequenos e mais vermel hos que a cor dominante do plasma; trama porfírica;

fragmentos xistosos.

Grãos com cores de interferência fortes (muitos fragmentos xistosos)

Fragmentos de carvão.

Agrotúbulos; opacos, em parte fragmentos de carvão.

Opacos, em parte fragmentos de carvão.

Opacos, em parte fragmentos de carvão.

Plasma bicolor sob nicóis cruzados.

Agrotúbulos; plasma bicolor sob nicóis cruzados.

Grupo 2. Solos de textura média a arenosa e hipoférricos

\begin{tabular}{|c|c|c|c|c|}
\hline N3A & A & $\begin{array}{l}\text { De grãos com películas e de grãos } \\
\text { interligados (inclusão com micro- } \\
\text { agregados entre grãos) }\end{array}$ & $\begin{array}{l}\text { De empacotamento e } \\
\text { canais }\end{array}$ & Fragmentos de carvão (opacos). \\
\hline N3A & $\mathrm{B}$ & $\begin{array}{l}\text { De grãos interligados e com } \\
\text { microagregados entre grãos } \\
\text { (inclusão de grãos com películas) }\end{array}$ & $\begin{array}{l}\text { De empacotamento e } \\
\text { canais }\end{array}$ & - \\
\hline N4A & A & $\begin{array}{l}\text { De grãos com películas e de grãos } \\
\text { interligados }\end{array}$ & $\begin{array}{l}\text { De empacotamento e } \\
\text { canais }\end{array}$ & $\begin{array}{l}\text { Nódulos são áreas de maior concentração de } \\
\text { plasma num fundo matricial dominado por } \\
\text { esqueleto de quartzo. }\end{array}$ \\
\hline N4A & $\mathrm{C}$ & $\begin{array}{l}\text { De grãos com películas e de grãos } \\
\text { interligados }\end{array}$ & $\begin{array}{l}\text { De empacotamento e } \\
\text { canais }\end{array}$ & $\begin{array}{l}\text { Nódulos como os do horizonte A, sendo mais } \\
\text { distintos. }\end{array}$ \\
\hline N5A & A & $\begin{array}{l}\text { De grãos interligados e de grãos } \\
\text { com películas }\end{array}$ & $\begin{array}{l}\text { De empacotamento, } \\
\text { canais e fissuras }\end{array}$ & $\begin{array}{l}\text { Partes do fundo matricial com mais plasma são } \\
\text { de menor pedalidade; opacos, em parte } \\
\text { fragmentos de carvão. }\end{array}$ \\
\hline N5A & $\mathrm{B}$ & $\begin{array}{l}\text { De grãos interligados e de grãos } \\
\text { com películas (inclusão com } \\
\text { microagregados entre grãos) }\end{array}$ & De empacotamento & $\begin{array}{l}\text { Microagregados com muitos fragmentos de } \\
\text { quartzo (tamanho de silte). }\end{array}$ \\
\hline T3A & A & $\begin{array}{l}\text { De grãos com películas e de grãos } \\
\text { interligados (inclusão com } \\
\text { microagregados entre grãos) }\end{array}$ & De empacotamento & Microagregados como em N5A, horizonte Bw. \\
\hline T3A & B & $\begin{array}{l}\text { De grãos interligados e de grãos } \\
\text { com películas }\end{array}$ & De empacotamento & - \\
\hline \multicolumn{5}{|c|}{ Grupo 3. Solos de textura argilosa a muito argilosa e férricos } \\
\hline T4A & A & Granular adensada e granular & De empacotamento & Muito fragmento opaco no plasma. \\
\hline T4B & $A$ & Granular adensada e granular & De empacotamento & Muito fragmento opaco no plasma. \\
\hline $\mathrm{T} 4 \mathrm{~A}$ & B & Granular e granular adensada & De empacotamento & $\begin{array}{l}\text { Muito fragmento opaco no plasma; raízes finas } \\
\text { e fragmentadas; parte dos nódulos são porosos. }\end{array}$ \\
\hline T4B & $\mathrm{B}$ & $\begin{array}{l}\text { Granular (inclusão granular } \\
\text { adensada) }\end{array}$ & De empacotamento & Muito fragmento opaco no plasma. \\
\hline T5A & $A$ & $\begin{array}{l}\text { Granular adensada e de canais } \\
\text { (inclusão granular) }\end{array}$ & $\begin{array}{l}\text { De empacotamento e } \\
\text { canais }\end{array}$ & $\begin{array}{l}\text { Muito fragmento opaco no plasma; grãos de } \\
\text { cal cedônea. }\end{array}$ \\
\hline T5B & $A$ & Granular adensada e granular & De empacotamento & $\begin{array}{l}\text { Muito fragmento opaco no plasma; grãos de } \\
\text { cal cedônea. }\end{array}$ \\
\hline T5A & $\mathrm{B}$ & $\begin{array}{l}\text { Granular (inclusão granular } \\
\text { adensada) }\end{array}$ & De empacotamento & $\begin{array}{l}\text { Muito fragmento opaco no plasma; grãos de } \\
\text { cal cedônea; opacos, em parte fragmentos de } \\
\text { carvão. }\end{array}$ \\
\hline T5B & $\mathrm{B}$ & Granular adensada e granular & De empacotamento & Muito fragmento opaco no plasma. \\
\hline
\end{tabular}


e9c) ea maior freqüência deciclos de umedecimento e secagem sobre os horizontes superficiais prejudicam a definição dos mi croagregados, além de impingir-Ihes mai or coalescência, promovendo deformações mecânicas que Ihes aumentam o tamanho (Vidal-Torrado et al., 1999).

Observa-se presença constante de pequenos fragmentos opacos (carvão) no plasma de materiais dos horizontes $A$ dos perfis sob vegetação nativa de cerrado (mais bem observados na figura $9 \mathrm{~g}$ ), fato que pode estar associado à el evada freqüência do fogo nessetipo de vegetação (Furley, 1996; Furley, 1999). Os fragmentos de carvão são semel hantes àqueles encontrados em microagregados de origem biológica de Latossolos com horizonte A húmico por Silva \& Vidal-Torrado (1999). A presença de fragmentos de carvão maiores, soltos no fundo matricial, também
ocorre(Figura 9a). Nos perfis do Grupo 3, a presença dos opacos se acentua muito (Quadros 6 e 7 e Figura 11h), independentemente do horizonte analisado e do tamanho do fragmento, boa parte engl obando acumulações ferruginosas herdadas do material de origem (basalto) ou sendo produtos de alteração de minerais do próprio basalto.

A presença deum plasma manchado de vermel ho, com vários nódulos e agregados dessa cor no perfil G2A (Figura 8e), serviu para confirmar a presença de $\mathrm{Hm}$ nos agregados residuais da sua fração areia grossa, detectada pela DRX (Quadro 5 e Figuras 2b e 5). I gualmente, serve para reforçar a hipótese de que nos perfis associados à superfícieSul-Americana de G, a ocorrência de Latossolo Vermelho-Amarelo e LA na posição G2 possa estar relacionada com um pedoambiente mais úmido (Motta et al., 2002), por

Quadro 7 Quantitativos de características micromorfológicas de perfis de solo selecionados, agrupados pela textura e teor de Fe do ataque sulfúrico dos solos

\begin{tabular}{|c|c|c|c|c|c|c|c|c|}
\hline \multirow{2}{*}{ Perfil } & \multirow{2}{*}{ Horizonte } & \multicolumn{5}{|c|}{ E squeleto } & \multirow{2}{*}{ Plasma } & \multirow{2}{*}{ Poros } \\
\hline & & Quartzo & Outro mineral & Opaco & Nódulos & Raiz & & \\
\hline \multicolumn{9}{|c|}{ Grupo 1. Solos de textura argilosa a muito argilosa e hipo a mesoférricos } \\
\hline GIA & $A$ & 5 & traços & traços & traços & 6 & 48 & 41 \\
\hline G1A & $\mathrm{B}$ & 7 & 0 & traços & traços & traços & 53 & 40 \\
\hline G2A & $A$ & 16 & traços & traços & traços & 2 & 44 & 38 \\
\hline G2A & B & 15 & traços & 0 & 7 & traços & 47 & 31 \\
\hline G4A & A & 23 & 1 & traços & traços & traços & 50 & 26 \\
\hline G4A & B & 15 & 1 & 0 & 3 & 2 & 54 & 25 \\
\hline N 1A & $A$ & 35 & traços & 2 & 0 & 2 & 35 & 26 \\
\hline N IA & B & 29 & traços & traços & 0 & 1 & 42 & 28 \\
\hline N2A & $A$ & 38 & 0,5 & 0,5 & traços & 2 & 33 & 26 \\
\hline $\mathrm{N} 2 \mathrm{~A}$ & B & 33 & traços & 0 & 0 & 1 & 41 & 25 \\
\hline T1A & $A$ & 28 & 1 & traços & 0 & 2 & 39 & 30 \\
\hline T1A & B & 26 & 1 & traços & traços & traços & 40 & 33 \\
\hline T2A & $A$ & 9 & traços & 2 & traços & 3 & 47 & 39 \\
\hline $\mathrm{T} 2 \mathrm{~A}$ & B & 8 & traços & 1 & traços & traços & 55 & 36 \\
\hline \multicolumn{9}{|c|}{ Grupo 2. Solos de textura média a arenosa e hipoférricos } \\
\hline N3A & A & 58 & traços & traços & traços & 1 & 26 & 15 \\
\hline N3A & B & 44 & 1 & 0 & traços & traços & 27 & 28 \\
\hline $\mathrm{N} 4 \mathrm{~A}$ & A & 53 & 1 & 1,5 & 1 & 0,5 & 8 & 35 \\
\hline $\mathrm{N} 4 \mathrm{~A}$ & $\mathrm{C}$ & 47 & 1,5 & 2 & 2,5 & 0,5 & 8,5 & 38 \\
\hline N5A & $A$ & 40,5 & 1 & 2 & traços & 0,5 & 29 & 27 \\
\hline N5A & B & 34 & 1 & 1 & traços & traços & 31,5 & 32,5 \\
\hline T3A & $A$ & 46 & 1 & traços & 0 & 1 & 21 & 31 \\
\hline T3A & B & 45 & traços & 1 & 0 & 0 & 20 & 34 \\
\hline \multicolumn{9}{|c|}{ Grupo 3. Solos de textura argilosa a muito argilosa e férricos } \\
\hline T4A & A & 6,5 & traços & 1 & traços & 1 & 57,5 & 34 \\
\hline $\mathrm{T} 4 \mathrm{~B}$ & A & 4,5 & traços & 1 & 1 & 1,5 & 49 & 43 \\
\hline T4A & $\mathrm{B}$ & 4 & traços & 3 & traços & 2 & 42 & 49 \\
\hline $\mathrm{T} 4 \mathrm{~B}$ & $\mathrm{~B}$ & 4,5 & traços & 2 & 3 & traços & 47,5 & 43 \\
\hline T5A & $A$ & 3 & 2 & 1 & 2 & 1 & 52 & 39 \\
\hline T5B & $A$ & 5 & traços & 1 & 2 & 1 & 45,5 & 45,5 \\
\hline T5A & B & 3 & 2 & 1 & 1 & 1 & 45 & 47 \\
\hline T52 & B & 3,5 & 1 & 2 & 2,5 & 1 & 48 & 42 \\
\hline
\end{tabular}


ser a posição $\mathrm{G} 1$ relativamente mais elevada que G2 (Figura 12). Se a característica mais típica do plasma de Oxissolos é sua homogeneidade, como de todo o fundo matricial, decorrente da grande pedoturbação (Stoops \& Buol, 1985), no mínimo, é inesperada a presença desse plasma amarelo com várias "feições" vermel has, corroborando a hipótese anterior.
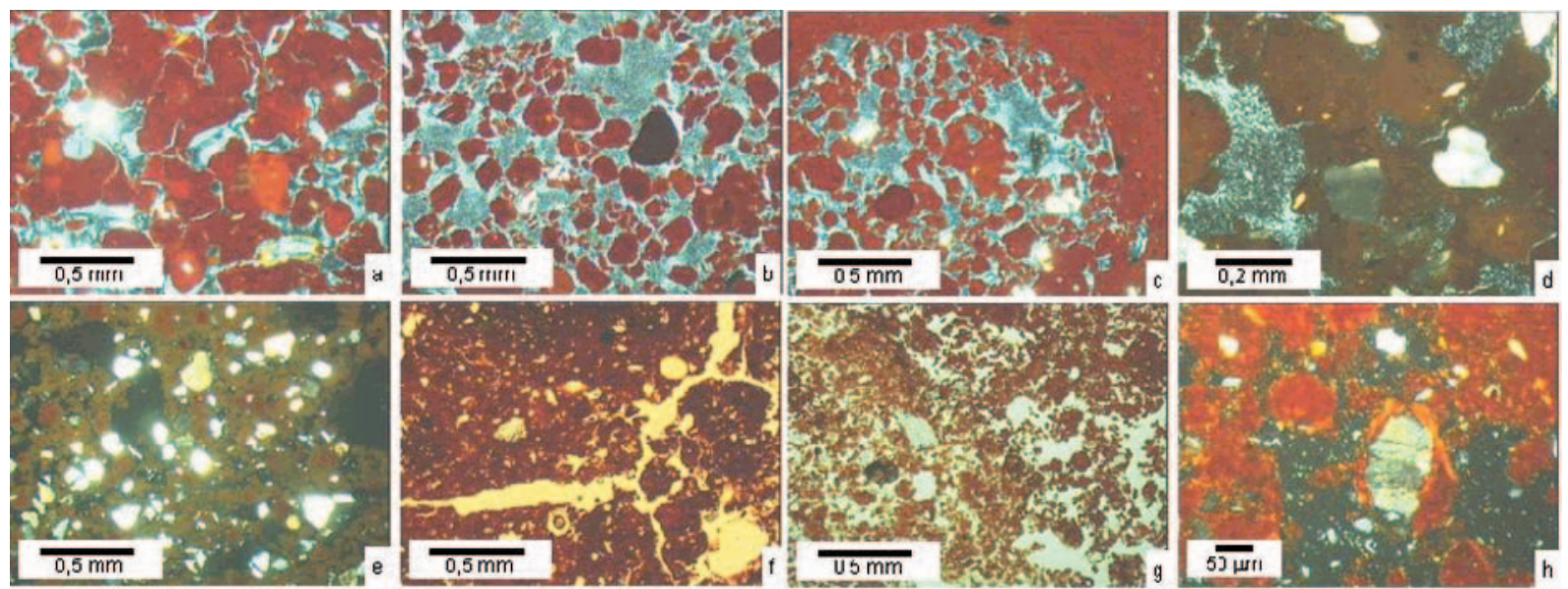

Figura 8. Micrografias de materiais dos perfis do Grupo 1 (solos de textura argilosa a muito argilosa e hi po a mesoférricos), perfis do leste de Goiás. G1A (LVw típico), horizonte A: dominância de estrutura granular adensada, alguns agregados com plasma menos vermelho que o restante, raízes e canais provenientes de atividade biológica (a); G1A, horizonte B w: estrutura granular, elevada porosidade (b); G1A, horizonte Bw: agrotúbulo preenchido com microagregados, notando-se a perda de pedalidade de sua parede relativamente ao restante do fundo matricial (c); G2A (LAw típico), horizonte A: domi nância de estrutura granular adensada, pontuações escuras no interior dos agregados (d); G2A, horizonte Bw: estrutura granular e granular adensada, vários agregados com plasma mais vermelho que o restante (e); G4A (LVd típico), horizonte A: alvéolo (canais conectados), realçando elevada atividade biológica (f); G4A, horizonte Bw: dominância de estrutura granular adensada (g); G4A, horizonte Bw: concentração plásmica revestindo grão de quartzo (h) [micrografias (f) e (g) sob luz polarizada em um plano, sendo as restantes sob nicóis cruzados].
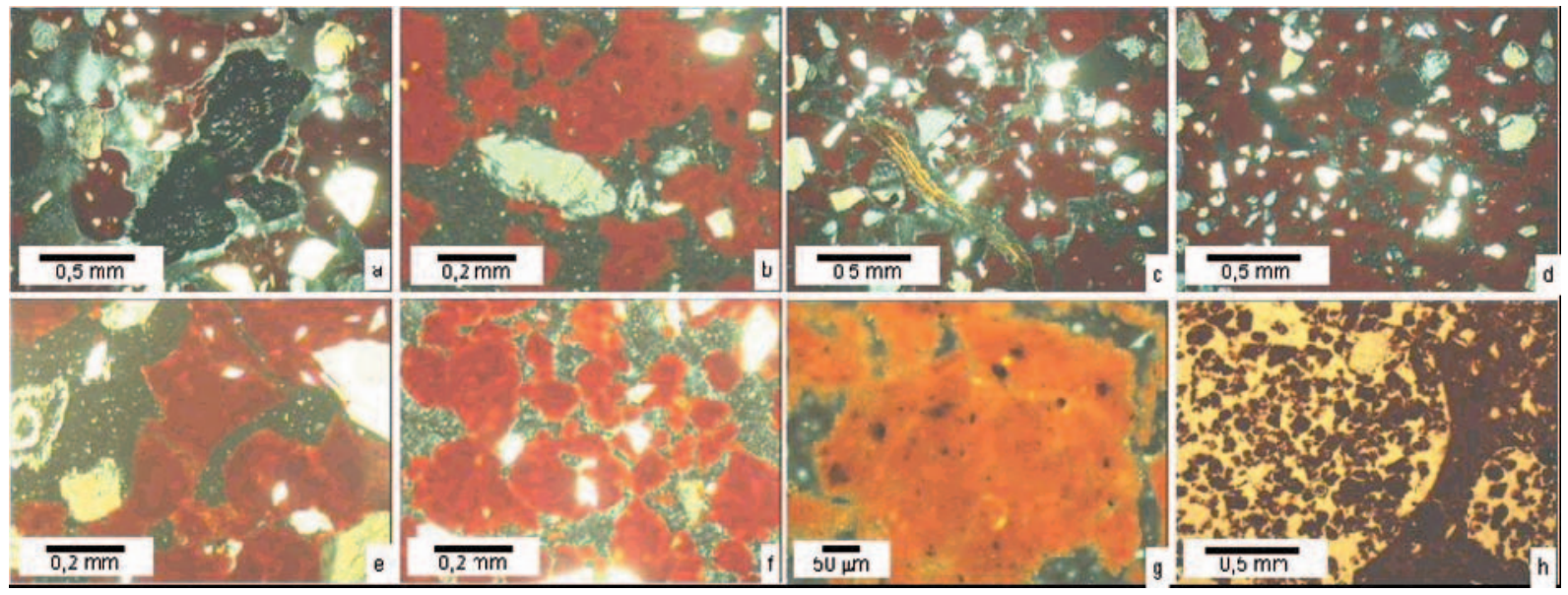

Figura 9. Micrografias de materiais de perfis do Grupo 1 (solos de textura argilosa a muito argilosa e hipo a mesoférricos), perfis do noroeste de Minas e do Triângulo Mineiro. N1A (LVd típico), horizonte A: microagregados (dominância de estrutura granular adensada) e fragmento de carvão (a); N1A, horizonte Bw: estrutura granular e granular adensada (b); N2A (L VAd típico), horizonte A: dominância de estrutura granular adensada, fragmento de raiz (c); N2A, horizonte Bw: dominância de estrutura granular adensada (d); T1A (LVd típico), horizonte A: microagregados limitados por canais de atividade biológica e porosidade conectada, fragmento de raiz (e); T1A, horizonte Bw: dominância de estrutura granular (f); T2A (LVAd típico), horizonte A: detalhe de microagregado, com muitas pontuações escuras (g); T2A, horizonte B w: agrotúbulo preenchido com microagregados, notando-se a perda de pedalidade de sua parede relativamente ao restante do fundo matricial (h) [micrografia (h) sob luz polarizada em um plano, sendo as restantes sob nicóis cruzados]. 


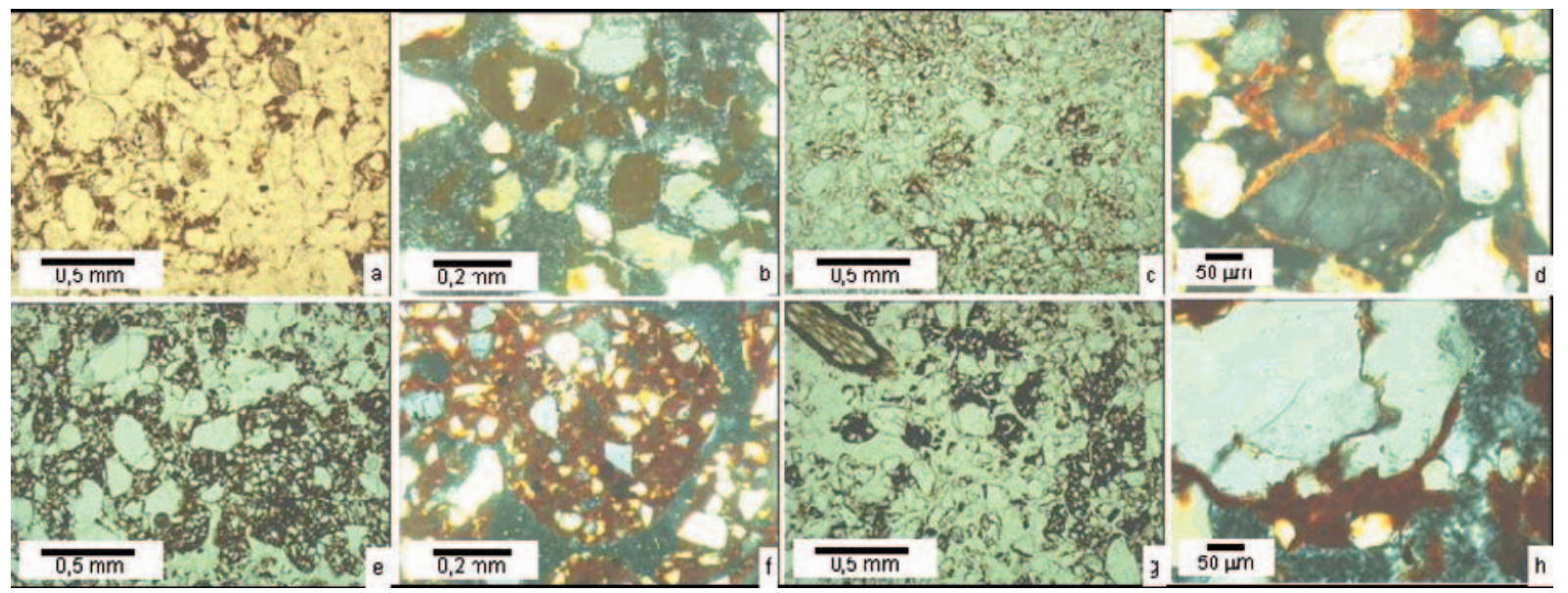

Figura 10. Micrografias de materiais de perfis do Grupo 2 (solos de textura média a arenosa e hipoférricos). N3A (LAd psamítico), horizonte A: estrutura de grãos inter ligados e de grãos com películas (a); N3A, horizonte Bw: agregados cercados de esqueleto de quartzo e poros (b); N4A (R Qo típico), horizonte A: estrutura de grãos interligados e de grãos com películas (c); N4A, horizonte C: detalhe de grão de quartzo revestido com plasma (d); N5A (LVd típico), horizonte A: estrutura de grãos interligados e de grãos com películas, sendo nítido domínios com mais (embaixo) e menos (em cima) plasma (e); N5A, horizonte Bw: mi croagregado bem individualizado, com muito quartzo (f); T3A (LVd psamítico), horizonte A: estrutura de grãos com películas e de grãos interligados, fragmento de raiz (g); T3A, horizonte Bw: detalhe de grãos de quartzo revesti dos e interligados por plasma (h) [micrografias (a), (c), (e) e (g) sob luz polarizada em um plano, sendo as restantes sob nicóis cruzados].
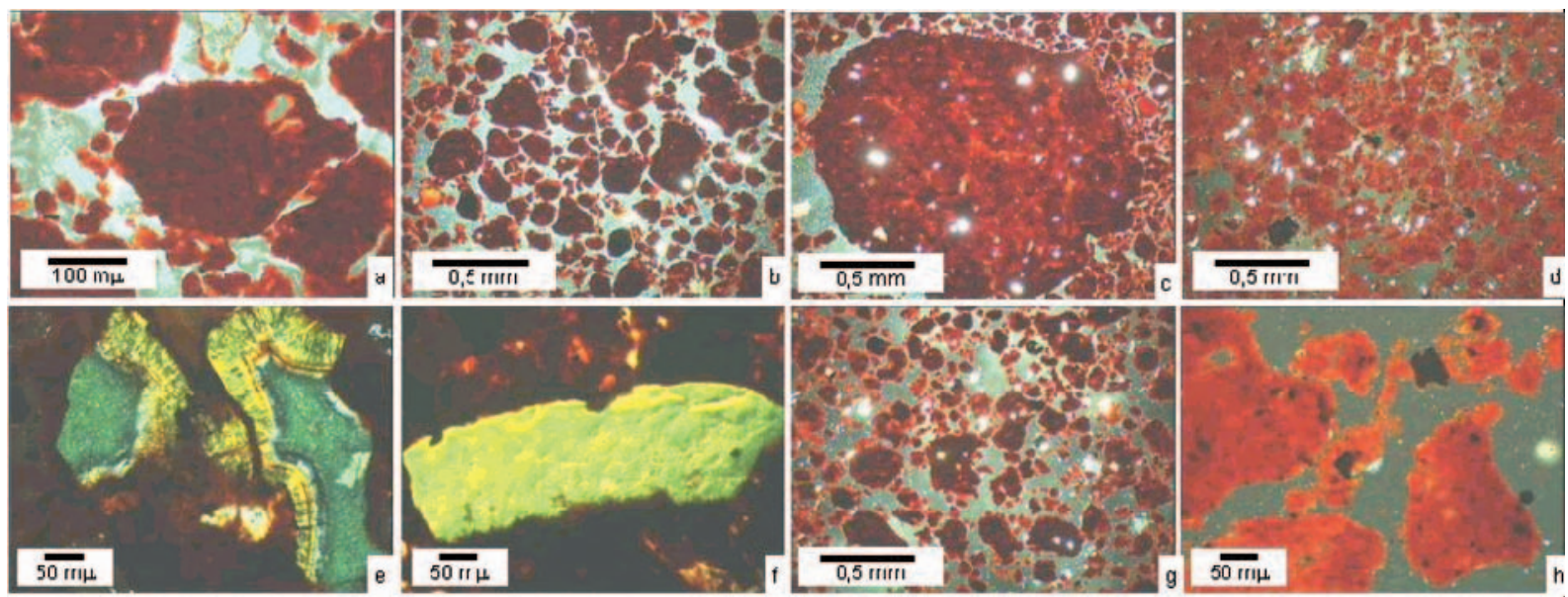

Figura 11. Micrografias de materiais de perfis do Grupo 3 (solos de textura argilosa a muito argilosa e férricos). T4B (LVdf típico), horizonte A: detalhe de agregados, por vezes porosos (algo grumosos) (a); T4B, horizonte Bw: estrutura granular, plasma escuro (b); T4B, horizonte Bw: nódulo (c); T5B (LVwf típico), horizonte A: estrutura granular adensada e granular, opacos (d); T5A (LVdf típico), horizonte A: grão de calcedônea com aspecto de um geodo (e); T5A, horizonte A: pseudomorfo de biotita (f); T5A, horizonte B w: estrutura granular (g); T5A, horizonte Bw: detalhe de microagregados, pontuações e fragmentos opacos (h) [mi crografias sob nicóis cruzados].

Essas feições aver mel hadas podem ser interpretadas de dois modos distintos, mas ambos envolvem um pedoambiente relativamente mais úmido em $\mathrm{G} 2$ que em G1: (a) Os nódulos avermel hados seriam resquícios de um período em que todos, ou quase todos, os sol os das chapadas eram avermelhados. Com o posterior surgimento de condições mais úmidas, houve xantização dos horizontes superficiais, mas permaneceram al guns nódul os avermel hados de maior resitência. (b) Mesmo sendo bem drenados, os soIos na posição $\mathrm{G} 2$ podem ter mi crossítios onde ocorrem, temporariamente, condições de redução. Por difusão, decorrente do gradiente então estabelecido, o $\mathrm{Fe}^{2+}$ movimentar-se-ia para sítios mais bem oxigenados, ondese precipitaria na forma deHm. Esses sítios mais bem oxidados são os nódul os avermel hados. 


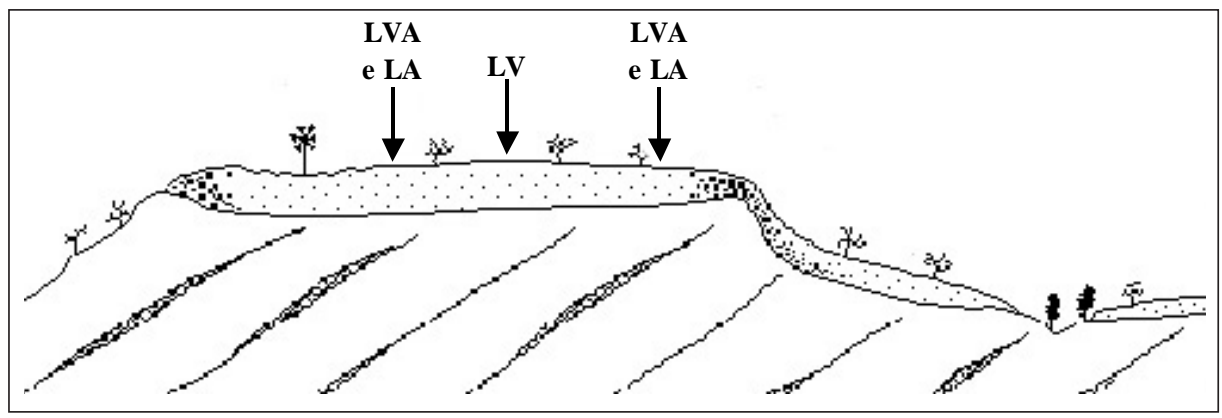

Figura 12. Representação esquemática da distribuição de Latossol os Vermel hos (LV), Vermel ho-Amarelos (LVA) e Amarelos (LA) na paisagem da primeira superfície do leste de Goiás (adaptado de Motta et al., 2002).

A única amostra em que poros de empacotamento não dominam a lâmina éo horizonte $A$ do perfil G4A, onde predominam canais, cavidades eal véol os (Quadro 6). O Grupo 3 apresenta as amostras com maior espaço poroso (média de $43 \%$ ). Os Grupos 1 e 2 são semel hantes em termos médios (respectivamente, 32 e $30 \%$ de poros), mas apresentam muita variabilidade entre os perfis de solo (Quadro 7). No Grupo 1, por exemplo, os perfis da superfície Sul-Americana de N (N1A e N2A) são menos porosos que os de $\mathrm{G}$ e T que ocorrem nessa mesma superfície, em consonância com o caráter mais caul inítico das amostras deN (Quadro 3), como já observado por Ferreira et al. (1999). De qualquer forma, a dominância de poros de empacotamento ajuda a explicar a el evada permeabilidade dos perfis estudados, conforme observações de campo.

Nódulos ferruginosos, como os já comentados opacos, ocorrem em todos os solos do Grupo 3, aspecto associado à influência de material máfico nos perfis deste grupo.

Os agrotúbulos provenientes de atividade biológica das amostras do horizonte $B$ dos perfis G1A, N 1A e T2A (Figuras 8c e 9h) apresentam a parede externa com plasma adensado e trama interna preenchida por microagregados e assemel ham-se aos pedotúbulos de Latossolos do norte de Minas, descritos por Oliveira et al. (2000).

\section{CONCLUSÕES}

1. O horizonte Bw dos Latossolos argilosos e muito argilosos estudados (Grupos 1 e 3), com relações de caul iníticas/(caul inita+gibbsita) variando de 0,27 a 0,77, apresenta grande coincidência de estrutura e microestrutura, respectivamente forte muito pequena granular e de microagregados (granular adensada ou granular).

2. Os solos do Grupo 2, Latossolos de textura média e um Neossolo Quartzarênico, apresentam o plasma preferencialmente como películas aderidas aos grãos que dominam o fundo matricial.
3. A presença marcante de agregados na fração areia, resistentes ao tratamento para dispersão da terra fina seca ao ar, ocorreu apenas nos Latossol os argilosos e muito argilosos do Grupo 3 (com caráter férrico) e em parte do Grupo 1 (naqueles mais gibbsíticos).

4. O horizonte Bw dos Latossolos Amarelos de mineralogia gibbsítica e isenta de hematita, da posição G2 do leste de Goiás, apresenta agregados residuais da fração areia e feições observadas em lâmina del gada (microagregados e nódulos) de cor vermelha e com hematita detectada pela difração de raios- $X$, que corroboram a hipótese de um pedoambiente mais úmido dessa posição relativamente à posição G1, com perfis de Latossolos Vermelhos.

\section{LITERATURA CITADA}

BARTOLI, F.; BURTIN, G. \& HERBILLON, A.J . Desaggregation and clay dispersion of Oxisols: Na resin, a recommended methodology. Geoderma, 49:301-317, 1991.

BREWER, R. Fabric and mineral analysis of soils. New York, R.E. Krieger, 1976. 482p.

BULLOCK, P.; FEDOROFF, N.; I ONJ ERIUS, A.; STOOPS, G. \& TURSINA, T. Handbook for soil thin section description. Wolverhampton, Waine Research Publications, 1985. 153p.

BUOL, S. W. \& ESWARAN, H. Oxisols. Adv. Agron., 68:151195, 2000.

CLINE, M.G. \& BUOL, S.W. Soils of the Central Plateau of Brazil and extension of results of field research conducted near Planaltina, Federal District, to them. Ithaca, Cornell University, 1973. 43p. (Agronomy Mimeo 73-13)

EMPRESA BRASILEIRA DE PESQUISA AGROPECUÁRIA EMBRAPA. Centro Nacional de Pesquisa de Solos. Manual de métodos de análise de solo. 2.ed. Rio de J aneiro, 1997. 212p. (EMBRAPA-CNPS. Documentos, 1)

EMPRESA BRASILEIRA DE PESQUISA AGROPECUÁRIA EMBRAPA. Centro Nacional de Pesquisa de Solos. Sistema brasileiro de classificação de solos. Brasília, Embrapa Produção de Informação; Rio de J aneiro, Embrapa Solos, 1999. $412 p$. 
FERREIRA, M.M.; FERNANDES, B. \& CURI, N. Mineralogia da fração argila e estrutura de $L$ atossol os da região Sudeste do Brasil. R. Bras. Ci. Solo, 23:507-514, 1999.

FITZPATRICK, E.A. Micromorphology of soils. London, Chapman and Hall, 1984. 433p.

FURLEY, P.A. The influence of slope on the nature and distribution of soils and plant communities in the Central Brazilian cerrado. In: ANDERSON, M.G. \& BROOKS, S.M., eds. Advances in Hillslope processes. New York, J ohn Wiley, 1996. v.1, p.327-346.

FURLEY, P.A. The nature and diversity of neotropical savanna vegetation with particular reference to the Brazilian cerrados. Global Ecol. Biog., 8:223-241, 1999.

GOMES, J.B.V.; CURI, N.; MOTTA, P.E.F.; KER, J.C.; MARQUES, J.J.G.S. \& SCHULZE, D.G. Análise de componentes principais de atributos físicos, químicos e mineralógicos de sol os do bioma Cerrado. R. Bras. Ci. Solo, 28:137-153, 2004

KALIMA, C. \& SPAARGAREN, O. Oxisols in Zambia. In: INTERNATIONAL SOIL CLASSIFICATION WORKSHOP: CLASSIFICATION, CHARACTERIZATION AND UTILIZATION OF OXISOLS, 8., Rio de J aneiro, 1986. Proceedings. Rio de J aneiro, EMBRAPA/SMSS/ATD/UPR, 1988. p.167-173.

KÄMPF, N. \& CURI, N. Óxidos deferro: indicadores deambientes pedogênicos egeoquímicos. Tópicos Ci. Solo, 1:107-138, 2000.

LEMOS, R.C. \& SANTOS, R.D. Manual de descrição e col eta de solo no campo. 2.ed. Campinas, Sociedade Brasileira de Ciência do Solo, 1996. 84p.

LIMA, P.C. Micromorfologia de "horizonte B" de Latossolos do Sudeste e do Sul do Brasil. In: REUNIÃO DE CLASSIFICAÇÃO, CORRELAÇÃO DE SOLOS E INTERPRETAÇÃO DE APTIDÃO AGRÍCOLA, 3., Rio de J aneiro, 1988. Anais. Rio de J aneiro, EMBRAPA-SNLCS/ SBCS, 1988. p.391-411.

LIMA, P.C.; CURI, N. \& LEPSH, I.F. Terminologia de micromorfol ogia do solo. Boletim I nf. SBCS, 10:33-43, 1985.

MARQUES, J .J .G.S.M. Trace element distributions in Brazilian cerrado soils at the landscape and micrometer scales. West Lafayette, PurdueUniversity, 2000. 172p. (Tese de Doutorado)

MOTTA, P.E.F.; CARVALHO FILHO, A.; KER, J .C.; PEREIRA, N.R.; CARVALHO J ., W. \& BLANCANEAUX,P. Relações solo-superfície geomórfica e evolução da paisagem em uma área do Planalto Central Brasileiro. Pesq. Agropec. Bras., 37:869-878, 2002.

OADES, J .M. \& WATERS, A.G. Aggregate hierarchy in soils. Aust. J . Soil Res., 29:815-828, 1991.

OLIVEIRA, C.V.; KER, J.C.; DUARTE, M.N.; CURI, N.\& FONTES, L.E.F. Atributos micromorfológicos de solos do projeto J aíba, norte de Minas Gerais. R. Bras. Ci. Solo, 24:117-128, 2000.
PINHEIRO-DICK, D. \& SCHWERTMANN, U. Microaggregates from Oxisols and Inceptisols: dispersion through selective dissolutions and physicochemical treatments. Geoderma, 74:49-63, 1996

RESENDE, M.; BAHIA F., A.F.C. \& BRAGA, J M. Mineralogia da argila de Latossolos estimada por alocação a partir do teor total de óxidos do ataque sulfúrico. R. Bras. Ci. Solo, 11:17-23, 1987

RESENDE, M.; CURI, N.; REZENDE, S.B. \& CORRÊA, G.F. Pedologia: base para distinção de ambientes. Viçosa, NEPUT, 2002. 338p.

SANTOS, M.C.D.; MERMUT, A.R. \& RIBEIRO, M.R Submicroscopy of clay microaggregates in an Oxisol from Pernambuco, Brazil. Soil Sci. Soc. Am. J ., 53:1895-1901, 1989.

SCHAEFER, C.E.R. Brazilian Latosols and their B horizon microstructure as long-term biotic constructs. Aust. J . Soil Res., 39:909-926, 2001.

SCHULZE, D.G. \& STOTT, D.E. Soil structure alteration: the role of soil mineralogy, chemistry, and microbiology. In: CONGRESSO BRASILEIRO DE CIÊNCIA DO SOLO, SOCIEDADE BRASILEIRA DE CIÊNCIA DO SOLO/ EMPRESA BRASILEIRA DE PESQUISA AGROPECUÁRIA, 26., Rio de J aneiro, 1997. Anais. Rio de J aneiro, 1997. 19p. CD-ROM

SILVA, A.C. \& VIDAL-TORRADO, P. Gênese dos Latossolos Húmicos e sua relação com a evolução da paisagem numa área cratônica do sul de Minas Gerais. R. Bras. Ci. Solo, 23:329-341, 1999.

STOOPS, G.F. \& BUOL, S.W. Micromorphology of Oxisols. In: DOUGLAS, L.A. \& THOMPSON, M.L., eds. Soil micromorphology and soil classification. Madison, Soil Science Society of America, 1985. p.105-119. (SSSA. Special Publication, 15)

VIDAL-TORRADO, P. \& LEPSH, I.F. Morfogênese dos solos de uma toposseqüência com transição $B$ latossólico/B textural sobre migmatitos em Mococa (SP). R. Bras. Ci. Solo, 17:109119, 1993

VIDAL-TORRADO, P.; LEPSH, I.F.; CASTRO, S.S. \& COOPER, M. Pedogênese em uma seqüência Latossolo-Podzólico na borda de um platô na Depressão Periférica Paulista. R. Bras. Ci. Solo, 23:909-921, 1999.

VIDAL-TORRADO, P. \& LEPSH, I.F. Relações material de origem/solo e pedogênese em uma seqüência de solos predominantemente argil losos e latossólicos sobre psamitos na Depressão Periférica Paulista. R. Bras. Ci. Solo, 23:357369, 1999.

VITORINO, A.C.T. Relação da mineralogia e química do solo com a dispersão de argila e estabilidade de agregados do tamanho silte. Lavras, Universidade Federal de Lavras, 2001. 79p.

VRDOLJ AK, G.A. Ultramicroscopy of a Brazilian Oxisol. Berkeley, University of California, Berkeley,1998. CDROM. (Tese de Doutorado) 